\title{
Failure analysis of Monastery of Jerónimos, Lisbon: How to learn from sophisticated numerical models
}

\author{
P.B. Lourenço *, K.J. Krakowiak, F.M. Fernandes, L.F. Ramos \\ Department of Civil Engineering, University of Minho, Azurém, P - 4800-058 Guimarães, Portugal
}

Available online 30 March 2006

\begin{abstract}
Conservation and restoration of historical structures are still a challenge to modem practitioners even if significant research advances have occurred in the last decades. Significant advances have been made in non-destructive testing, mechanical characterization, tools for advanced numerical analysis, knowledge on traditional materials and techniques, and innovative materials and techniques. In the paper, Monastery of Jerónimos in Lisbon, Portugal is adopted as a case study for structural safety assessment. A first discussion is held on the difficulties related to the need of adopting simplified geometries of the model. After a set of sophisticated non-linear failure analyses, a second discussion is held with respect to the consequences associated with the results obtained. Finally, additional in situ testing and monitoring are carried out in a truly iterative process of knowledge accumulation before defining any remedial measures.
\end{abstract}

(C) 2006 Elsevier Ltd. All rights reserved.

Keywords: Structural failures; Finite element analysis; Damage assessment; Non-destructive inspection; Failure analysis

\section{Introduction}

Time shows that many historical masonry constructions collapsed due to accidental actions such as earthquakes, but not only exceptional events affect historical constructions. Fatigue and strength degradation, accumulated damage due to traffic, wind and temperature loads, soil settlements and the lack of structural understanding of the original constructors are high risk factors for the architectural heritage. Therefore, structural analysis and safety assessment of historical masonry buildings are often necessary.

Masonry is a heterogeneous material that consists of units and joints. Units are such as bricks, blocks, ashlars, adobes, irregular stones and others. Mortar can be clay, bitumen, chalk, lime/cement based mortar, glue or other. The huge number of possible combinations generated by the geometry, nature and arrangement of units as well as the characteristics of mortars raises doubts about the accuracy of the term "masonry". Still, the mechanical behavior of the different types of masonry has generally a common feature: a very low tensile strength. This property is so important that it has determined the shape of ancient constructions. Nevertheless,

\footnotetext{
* Corresponding author. Tel.: +351 253 510200; fax: +351253510217.

E-mail addresses: pbl@civil.uminho.pt (P.B. Lourenço), konrad@civil.uminho.pt (K.J. Krakowiak), fmcpf@civil.uminho.pt (F.M. Fernandes),ramos@civil.uminho.pt (L.F. Ramos).
} 
the difficulties in performing advanced testing of ancient structures are quite large due to the innumerable variations of masonry, the variability of the masonry itself in a specific structure and the impossibility of reproducing it all in a specimen.

Several methods and computational tools are available for the assessment of the mechanical behavior of historical constructions. The methods resort to different theories or approaches, resulting in: different levels of complexity (from simple graphical methods and hand calculations to complex mathematical formulations and large systems of non-linear equations), different availability for the practitioner (from readily available in any consulting engineer office to scarcely available in a few research oriented institutions and large consulting offices), different time requirements (from a few seconds of computer time to a few days of processing) and, of course, different costs. It should be expected that results of different approaches are also different, but this is not a sufficient reason to prefer one method from the other. In fact, a more complex analysis tool does not necessarily provide better results. Most techniques of analysis are adequate, possibly for different applications, if combined with proper engineering reasoning. Nevertheless, accurate modeling requires a thorough experimental description of the material. The reader is referred to [1-3] for a more comprehensive discussion on these issues. A basic notion is softening, which is a gradual decrease of mechanical resistance under a continuous increase of deformation forced upon a material specimen or structure. It is a salient feature of soil, brick, mortar, ceramics, rock or concrete, which fail due to a process of progressive internal crack growth.

Recently, Recommendations for the Analysis, Conservation and Structural Restoration of Architectural Heritage have been approved by ICOMOS [4]. Structures of architectural heritage, by their very nature and history (material and assembly), present a number of challenges in conservation, diagnosis, analysis, monitoring and strengthening that limit the application of modern legal codes and building standards. The recommended methodology for completing a project is shown in Fig. 1, where an iterative process is clearly required, between the tasks of data acquisition, structural behavior, and diagnosis and safety. In particular, diagnosis and safety evaluation of the structure are two consecutive and related stages on the basis of which the effective need for and extent of treatment measures are determined. If these stages are performed incorrectly, the resulting decisions will be arbitrary: poor judgment may result in either conservative and therefore heavy-handed conservation measures or inadequate safety levels.

Here, Monastery of Jerónimos in Lisbon, is adopted as a case study of an attempt to use modern techniques and recommendations for the safety assessment of the compound. In particular, two different aspects are considered: (a) the safety of the full monastery compound under seismic loading, in which five different load

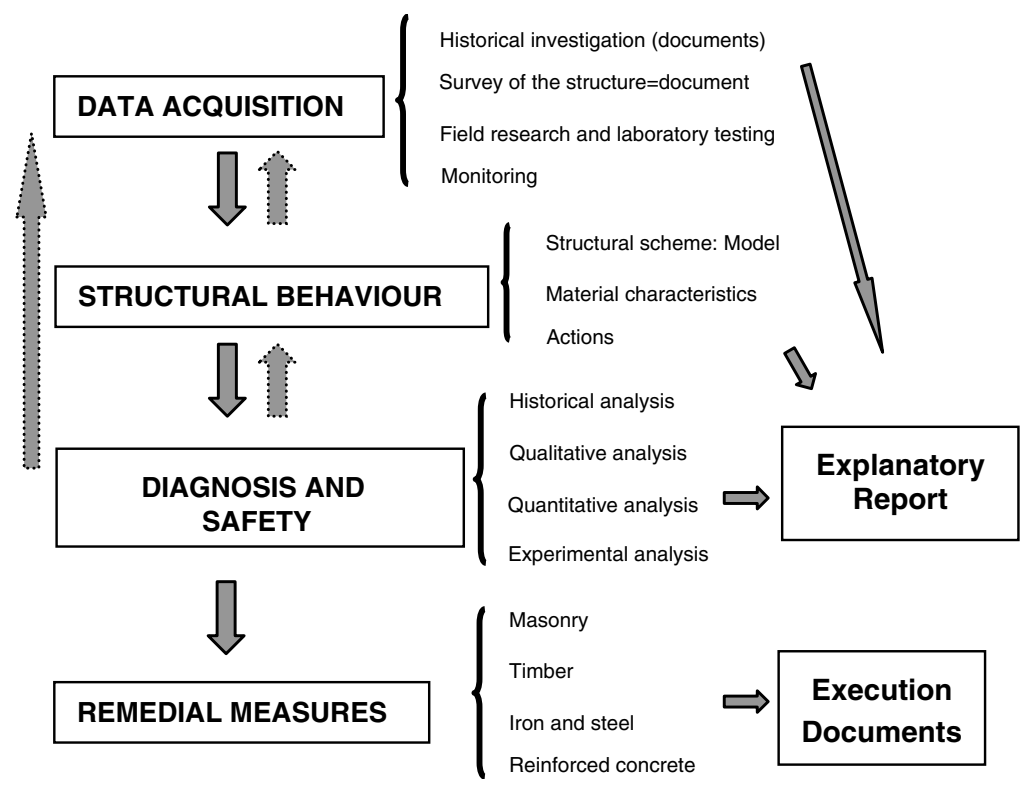

Fig. 1. Flowchart with the methodology for structural interventions proposed by ICOMOS [4]. 
combinations are assumed, including vertical loading and seismic action along two orthogonal directions (both positive or negative); (b) the safety of the church under vertical loading, in which only the dead load is assumed. For the purpose of structural assessment, the finite element method is used as analysis tool. Given the size and complexity of the structures considered, it is necessary to adopt finite element models that simplify the geometry to a great extent. From the results obtained, additional in situ testing and monitoring is proposed, aiming at later definition of appropriate remedial measures.

\section{Historical synopsis}

Monastery of Jerónimos is, probably, the crown asset of Portuguese architectural heritage. The construction of the monastery started in 1499 or 1500 . Due to the 5\% tax of the gold and spices from Africa and India, the construction initially planned by Diogo Boitaca was of gigantic size (four times the size of the actual monastery), including four cloisters and four dormitories. In fact, only one dormitory and one cloister were completed in the early times. The monastery is built with limestone (usually denoted by "lioz" type) quarried locally in Ajuda, Alcantara Valley, Laveiras, Rio Seco and Tercena. During the 16th century, the construction of the monument was carried out in three successive phases. The works in the 17th and 18th centuries are merely decorative or minor. In the 19th century, questionable works of re-composition or restoration were carried out and, in 1940, an attempt to correct previous mistakes and return the monastery to its original configuration was made.

The monumental set has considerable dimensions in plan, more than $300 \times 50 \mathrm{~m}^{2}$, and an average height of $20 \mathrm{~m}$ (50 $\mathrm{m}$ in the towers), see Fig. 2. The monastery evolves around two courts. The larger court is bordered by a long arcade of two levels that hosts the Ethnographic Museum of Archaeology and the Maritime Museum. The smaller court or the Cloister is bordered by the Church, the Sacristy, the Chapter Room and the Refectory.

The Gothic style was lately introduced in Portugal, incorporating a specific national influence. The socalled "Manueline" style (after King D. Manuel I), exhibits a large variety of architectural influences and erudite motives. An interesting aspect of the style appears in the 16th century, when the traditional three naves churches start to be replaced by a configuration with small difference in height for the naves. In the Church of Monastery of Jerónimos, the vault springs from one external wall to the other, supported in thin columns that divide almost imperceptibly the naves. From the traditional art, only the proportions and roof remain, being the concepts of space and structure novel. The fusion of the naves in the present Church is more obvious than in other manifestations of spatial Gothic. For this purpose, arches are no longer visible, the slightly curved vault comprises a set of ribs and the fan columns reduce effectively the free span. Additional information about the church and the vault can be found in [6].

\section{Global structural analysis of the compound}

The first analysis carried out focused in the behavior of the full monastery compound under seismic loading. The reason for this is the high hazard level in the region of Lisbon and the high cultural value of the monument. The compound resisted well to the earthquake of November 1, 1755. Later, in December 1756, a new earthquake collapsed one column of the church that supported the vaults of the nave and resulted in partial ruin of the nave. In this occasion also the vault of the high choir partially collapsed. In addition to these collapses, during the 19th century and later, several changes were made in the structure, namely additions connecting previously separated bodies, and changes in the structures of two towers and in the roofs. The effect of these changes in the seismic performance of the structure remained an open issue. For this purpose, nonlinear static (pushover) analysis was adopted. Pushover analysis is a non-linear static analysis carried out under conditions of constant gravity loads and monotonically increasing horizontal loads. This is a recommend methods to assess the structural performance of existing or retrofitted buildings for the purposes of EN 1998-3 [7].

\subsection{A refined model vs. a simplified model}

Aiming at validating the adopted modeling approach, a first model of the Refectory using three-dimensional volume elements and a refined geometry, the so-called refined model, was compared with a second 


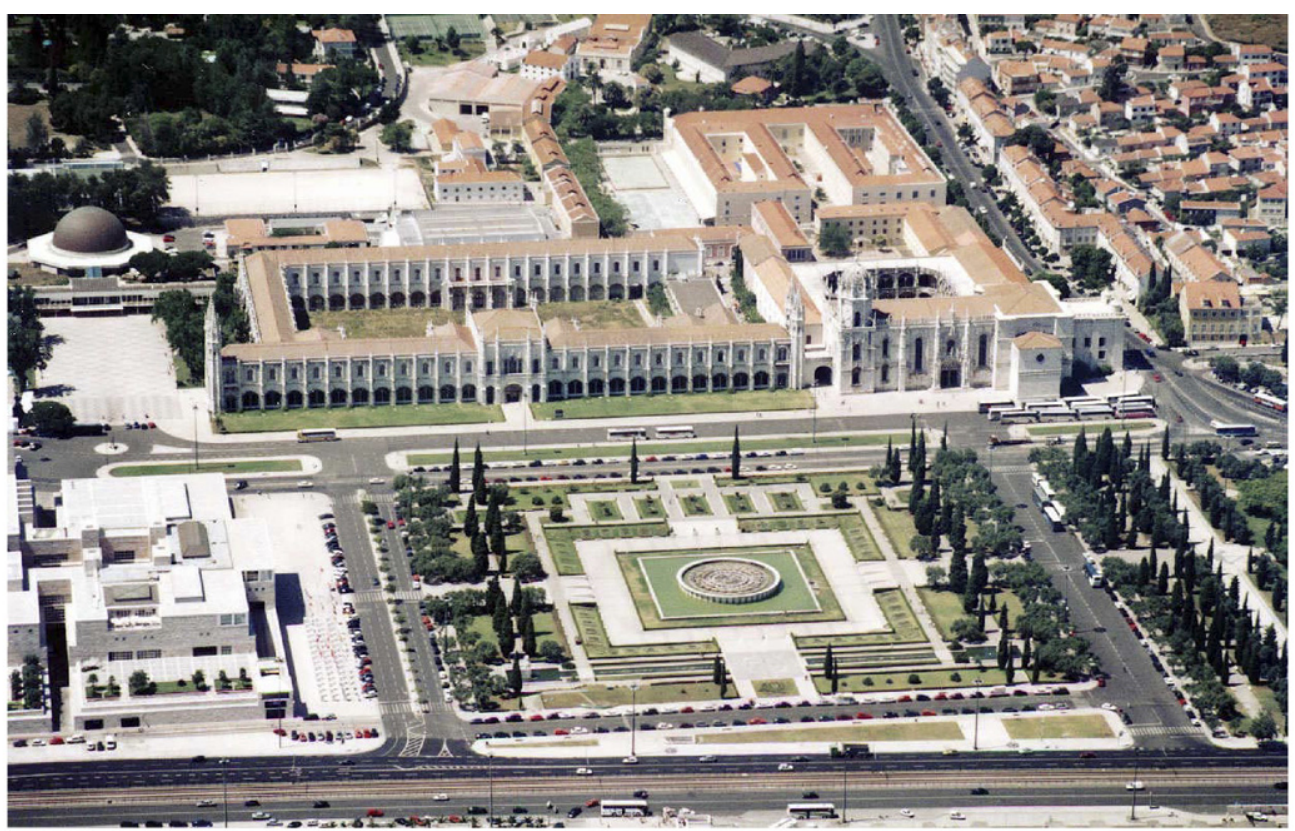

(a)

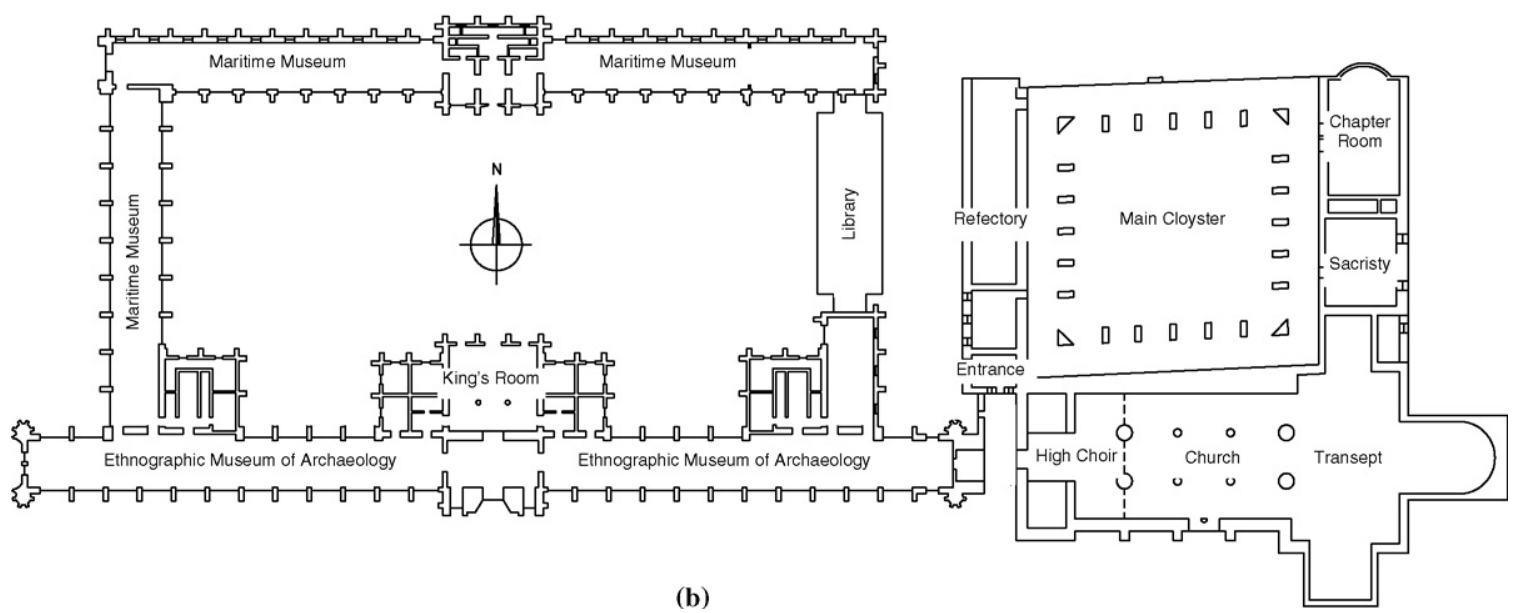

Fig. 2. Monumental set of Monastery of Jerónimos: (a) aerial view [5]; (b) plan.

model using shell elements and a very simplified geometry, the so-called simplified model, see Fig. 3 . The refined model included the openings with larger size and the actual thickness of the walls. Vaults were represented by curved, shell elements located at the center line of the elements. The simplified model did not include any openings, and the vaults were replaced by flat slabs. The slabs were located at the upper vault level because the vaults have a low curvature and it was observed that better results could be obtained by placing the flat slabs at this level, instead of placing the elements at the mass center of the vault. Additionally, in the simplified model, the vaults of the two compartments that form the entrance of the cloister were considered leveled and the staircase was substituted by a flat slab at medium height.

The models will be compared via a modal analysis because the main concern of the work is the performance under seismic action. The material properties are the same for both models: Young modulus $E=2700 \mathrm{~N} / \mathrm{mm}^{2}$ [8], Poisson ratio $v=0.2$ and a weight per unit volume of $23 \mathrm{kN} / \mathrm{m}^{3}$. In order to obtain similar results between the two models, the thickness of the walls in the simplified model had to be increased so that the bending 

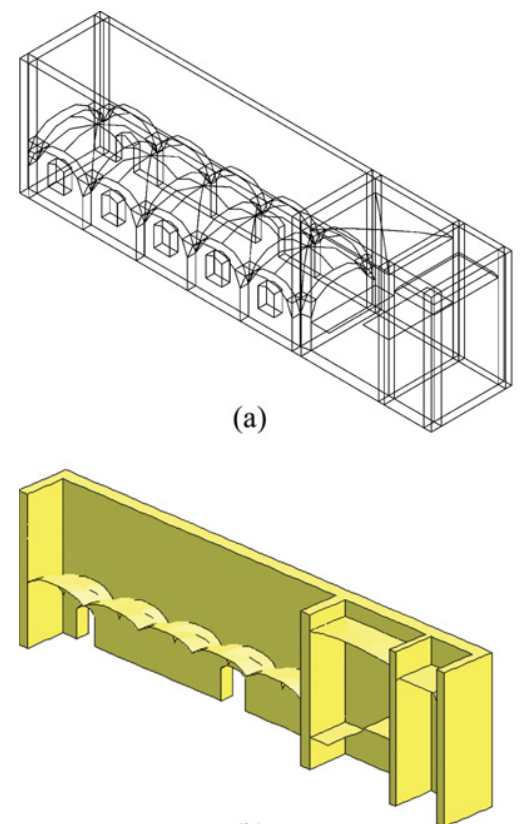

(b)
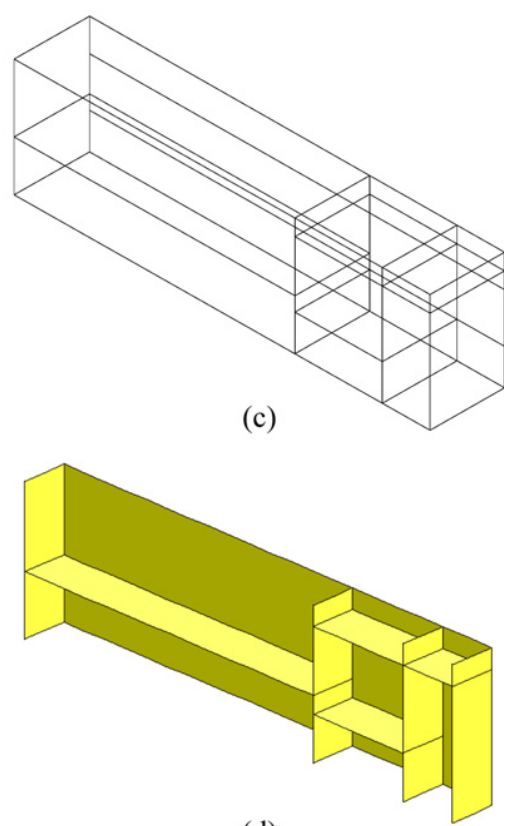

(d)

Fig. 3. Models adopted for the Refectory: refined model (a) view and (b) longitudinal cross-section; simplified model (c) view and (d) longitudinal cross-section.

stiffness of the walls includes the additional restraint effect of the nodes (associated with transverse-walls), see Fig. 4. This effect is usually neglected in modern buildings because the height to length ratio of the structural elements (typically in the range of $1 / 20$ in walls and $1 / 30$ in slabs) is much lower than the values observed in ancient buildings (in the range of $1 / 7$ for walls). It can be seen that, for shorter walls, the increase in thickness is up to $12 \%$, which results in an increase of stiffness of around $40 \%$, due to the cubic power of the thickness in the stiffness value. Without this correction the difference in the results is large [9]. Of course, it is debatable to adopt such a correction in the thickness for non-linear finite element analysis, due to the increase of strength of the corrected stiffness walls, associated to the square of thickness of a wall in case of a bending failure.

A modal analysis of the structure has been carried out and reasonable agreement is found between the refined and the simplified refined model, see Table 1 and Fig. 5. Table 1 shows the natural frequencies associated with the first six global vibration modes and the average difference is only $6 \%$ (the difference in mass has been compared and it is just 4\%). Nevertheless it is stressed that the simplified model exhibits a significantly large number of local modes due to the vertical modes associated with the flat slabs. For this reason, in Table 1, the frequencies have been compared only between equivalent global modes. In Fig. 5, the modal shapes associated with the three first frequencies are shown. It can be seen that the two first global modes agree well in shape, whereas the local 3rd mode is different in both models.

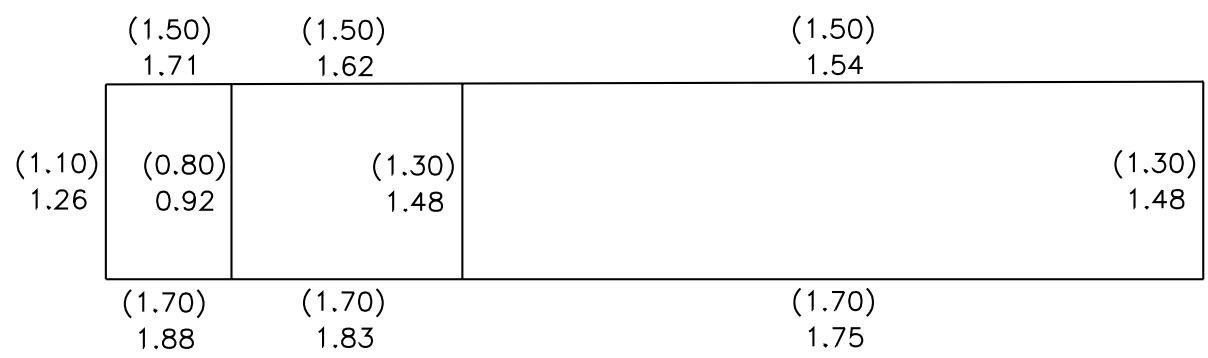

Fig. 4. Plan view with thicknesses of the walls (inside parentheses is the actual value and outside is the adopted value). 
Table 1

Natural frequencies $f$ associated with the first six global modal shapes (Hz)

\begin{tabular}{lllllll}
\hline Refined model & $f_{1}=1.79$ & $f_{2}=2.26$ & $f_{4}=3.34$ & $f_{5}=3.78$ & $f_{7}=4.70$ & $f_{8}=5.41$ \\
Simplified model & $f_{1}=1.61$ & $f_{2}=2.41$ & $f_{4}=3.25$ & $f_{7}=3.98$ & $f_{9}=4.39$ & $f_{12}=5.31$ \\
\hline
\end{tabular}

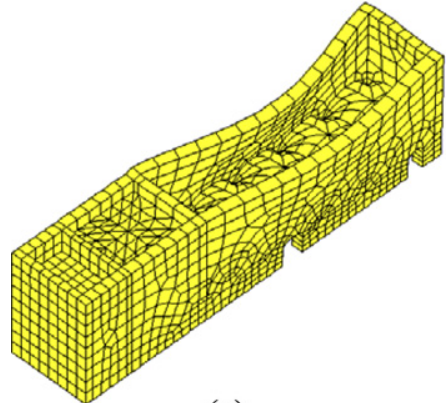

(a)

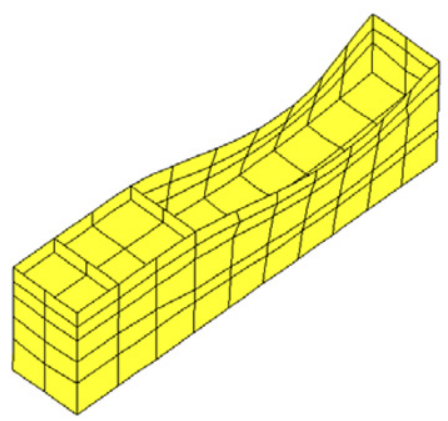

(d)

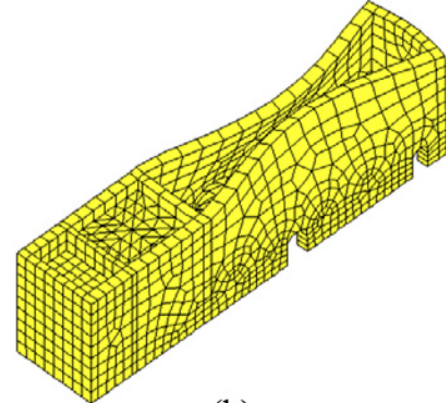

(b)

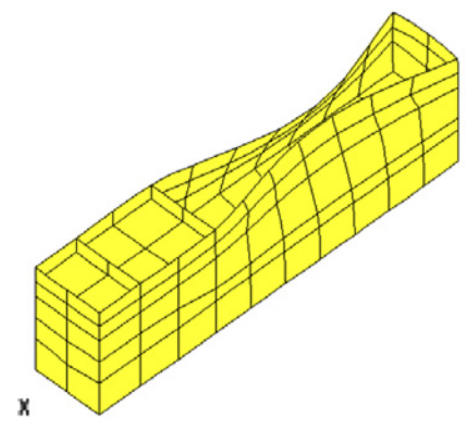

(e)

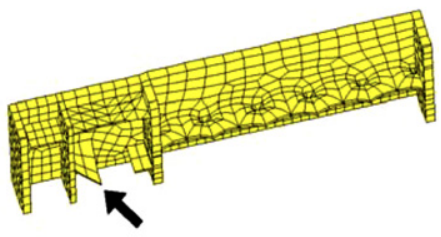

(c)

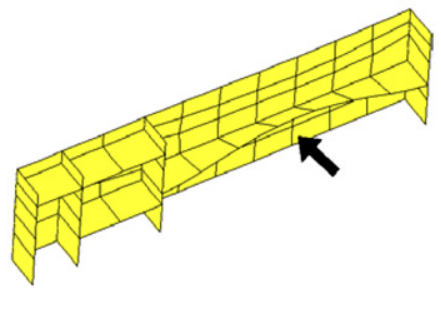

(f)

Fig. 5. Shape of the first three vibration modes: (a-c) refined model; (d-f) simplified model. Note that the two first modes are global and the third mode is local.

Of course that the local modes affect mostly the element selected and hardly the entire structure. It seems that it is possible to conclude that the corrected simplified model allows an adequate representation of the dynamic behavior of the construction. Thus, it is possible to conclude that the free vibration of the flat slabs should not be allowed in the analysis.

\subsection{Complete model of the Monastery}

In the complete model only the very large openings were considered. The geometry of the model was referred to the average surfaces of the elements. All the walls, columns, buttresses, vaults and towers were included in the model, with the exception of a few minor elements, Fig. 6. The vaults were, initially, represented as a flat slab with constant thickness due to their geometric complexity. The finite element mesh is predominantly rectangular and structured, but, for the towers and local refinements, triangular finite elements are also adopted. All elements possess quadratic displacement fields. The mesh includes around 8000 elements, 23,500 nodes and 135,000 degrees of freedom. The time-effort necessary for total mesh generation, including definition of supports, loads and thicknesses, can be estimated in three man-months.

A first analysis of the structure subjected to its self-weight has been carried out. The results clearly indicated that the initial mesh needed several corrections as the maximum displacements (up to $0.25 \mathrm{~cm}$ ) and maximum tensile stresses (up to $0.45 \mathrm{~N} / \mathrm{mm}^{2}$ ) were unacceptable. Fig. 7 illustrates these results. The mesh was corrected 


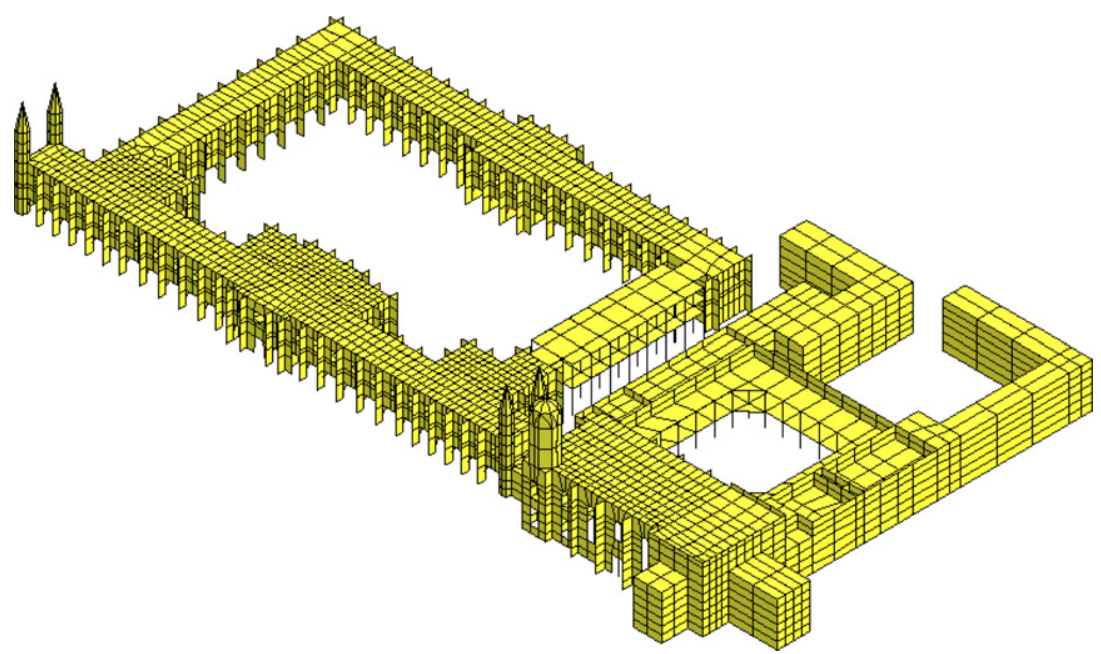

Fig. 6. Model of the complete Monastery.

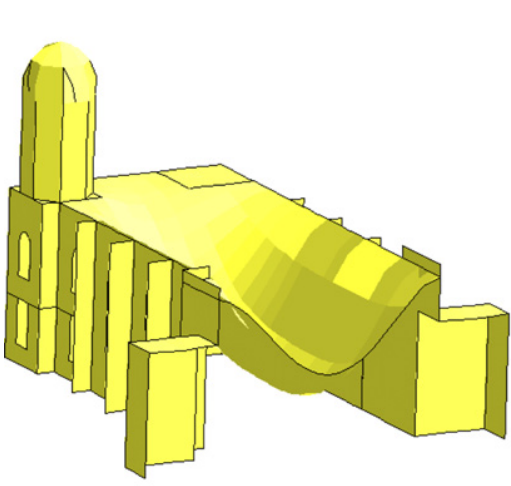

(a)

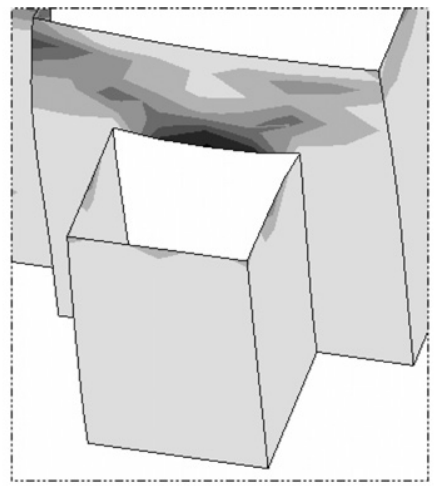

(b)

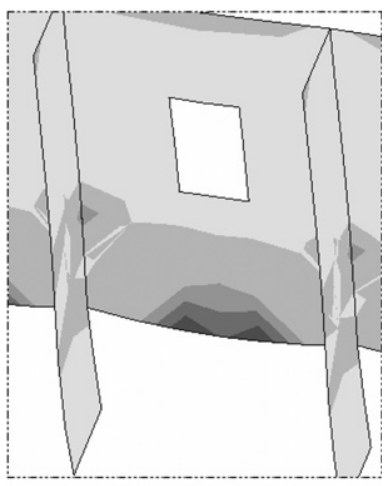

(c)

Fig. 7. Unacceptable results in the preliminary model: (a) large displacements at the vaults with constant stiffness; (b) large tensile stresses at the transept; (c) large tensile stresses at the arcade.

by introducing tyings at the flat shells, replacing the constant thickness of the vaults by variable thickness and introducing new elements to better represent the large openings, see Fig. 8. After these corrections, it was found that the maximum tensile stresses in the structure for vertical loading are still relatively large (up to $0.35 \mathrm{~N} / \mathrm{mm}^{2}$ ) and occur in the buttresses. These stresses are related to the double curvature of the buttresses associated with the flexural behavior of the flat slabs, see Fig. 9a, and are questionable. Namely, an outwards displacement due to the thrust action of the vault cannot be found in the present model. It can be also seen that the tensile stresses in the corrected areas have been significantly reduced, see Fig. 9b. Finally, it is stressed that the average compressive stresses seem adequate (around $0.7 \mathrm{~N} / \mathrm{mm}^{2}$ ), with higher values in the columns and in a wall not belonging to the monument, where little structural information exists.

\subsection{Safety assessment for earthquake actions}

The analyses carried out assuming linear elastic behavior of the material allowed to conclude that the tensile stresses present in the structure are reasonably high and above the tensile strength of masonry. For the safety assessment, five independent non-linear analyses were carried out, namely for vertical loads and for seismic loading along two directions (with positive and negative sign). According to the Portuguese Code, it was assumed that the horizontal loads equivalent to the seismic action are $22 \%$ of the vertical loads, magnified by a 


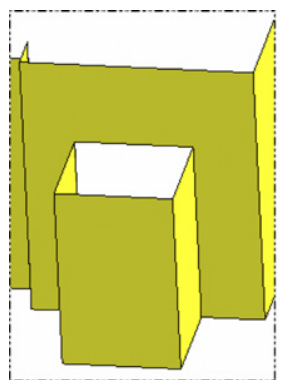

(a)

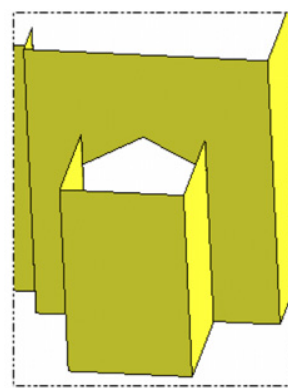

(b)

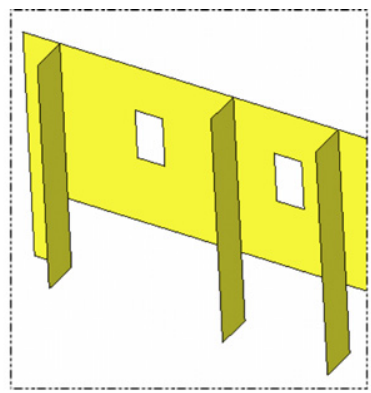

(c)

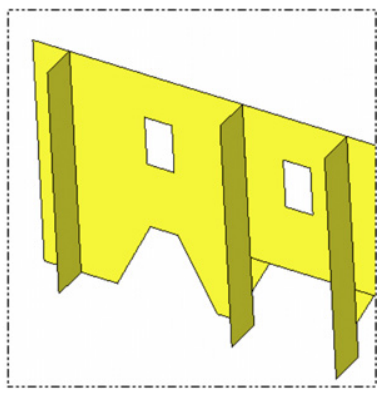

(d)

Fig. 8. Examples of the corrections in the geometry of the preliminary model: transept (a) before and (b) after correction; arcade (c) before and (d) after correction.

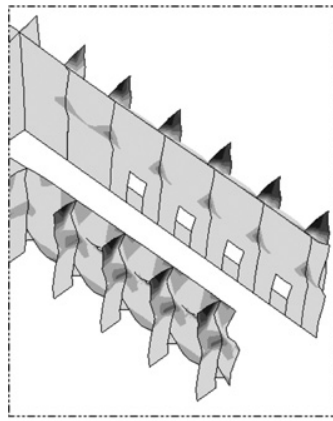

(a)

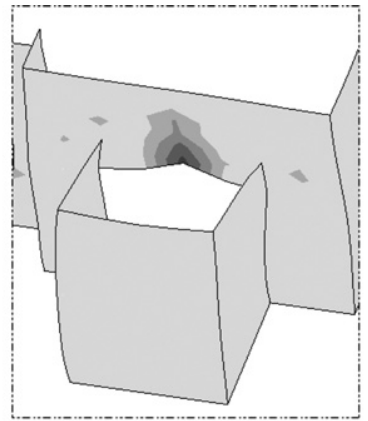

(b)

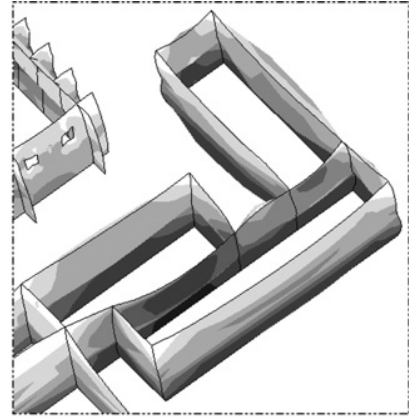

(c)

Fig. 9. Linear elastic results for vertical loads: (a) peak tensile stresses at the buttresses; (b) smaller tensile stresses at the transept; (c) peak compressive stresses in adjacent bodies of the monument.

loading safety factor of 1.5 . For the non-linear analyses, a tensile strength of $0.1 \mathrm{~N} / \mathrm{mm}^{2}$ was adopted [10]. Detailed information on the analyses can be found in [9].

For the design values of the loads, the deformed meshes of the analyses are given in Fig. 10 for seismic loading along two orthogonal directions: the longitudinal $X$ direction and the transversal $Z$ direction. It can be seen that the towers of the Museum are the critical structural elements featuring displacements of around $0.10 \mathrm{~m}$ in each case and cracks of around $0.01 \mathrm{~m}$. Other cracks are visible in the church, see Fig. 11 .

Fig. 12 indicates the areas of maximum compressive stresses, which reach values up to $4.0 \mathrm{~N} / \mathrm{mm}^{2}$. These values are very localized in the buttresses, in one of the bodies adjacent to the monument and in the arcade. Given the fact that this is an accidental loading condition and that the stresses are very localized, it is assumed that the structure is not at risk. The average maximum values are around $2.0-2.5 \mathrm{~N} / \mathrm{mm}^{2}$, which seem acceptable [10]. Finally, Fig. 13 shows the force-displacement diagram for the critical seismic loading, along the $Z$ axis. Here, the load factor represents the ratio between the design loads and the applied load and the displacement is the measured horizontal component at the tower top. The analysis was continued further until collapse of the tower, which occurred for a load 25\% higher than the applied design load, at a displacement larger than $0.25 \mathrm{~m}$.

\subsection{Conclusions}

A simplified model of Monastery of Jerónimos was presented. The validity of the model was assessed by a comparison of modal analysis between a simplified model and a refined model. The difficulties inherent to the adoption of simplified models were addressed. Namely, special care seems necessary when: (a) using shell elements in ancient buildings, as the out-of-plane bending stiffness of walls seems to become incorrect, and (b) using flat shells to represent complex vaults, as erroneous bending deformation of the walls seem to occur. 


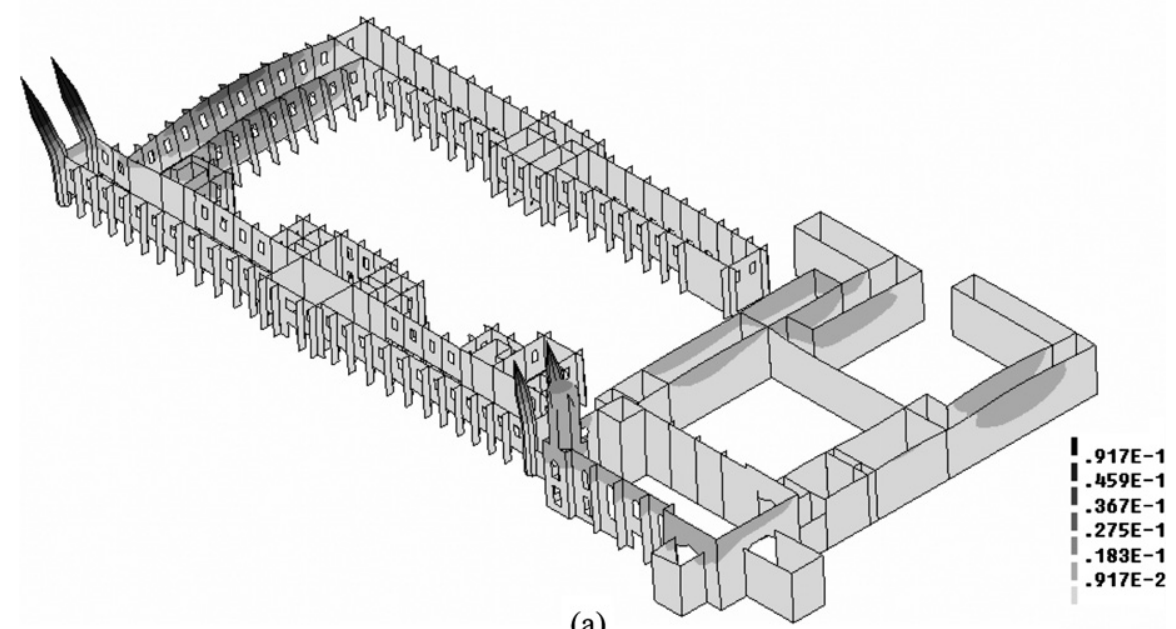

(a)

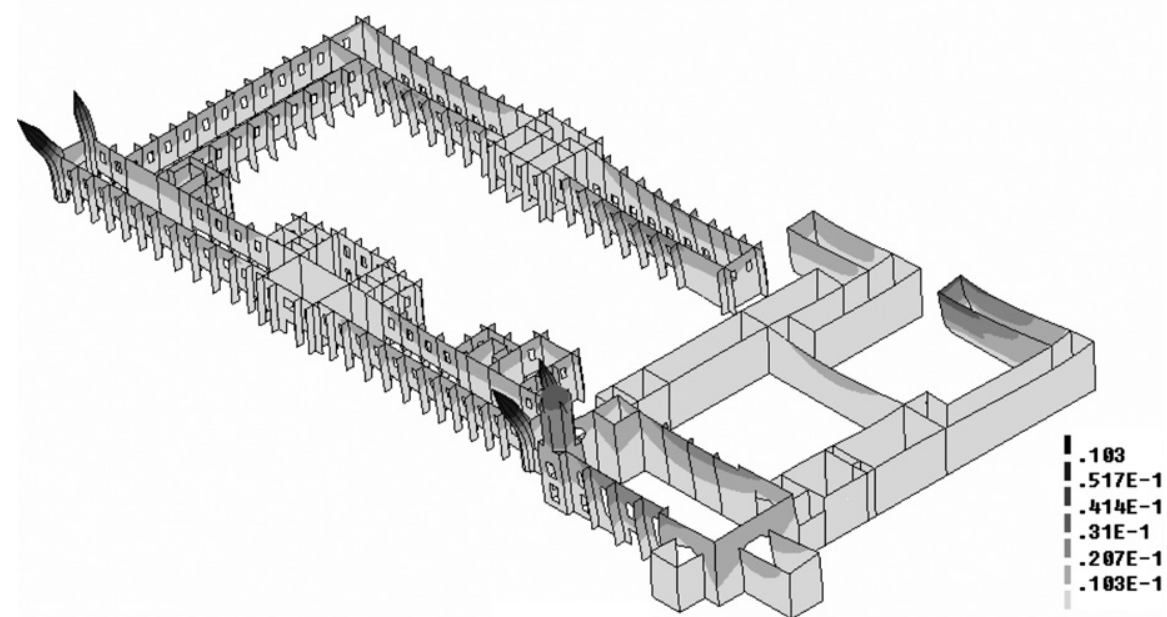

(b)

Fig. 10. Deformed meshes and contour of maximum displacements (maximum displacement for design loads is around $0.1 \mathrm{~m}$ ): seismic load along the (a) longitudinal $X$ and (b) transversal $Z$ axis of the model.

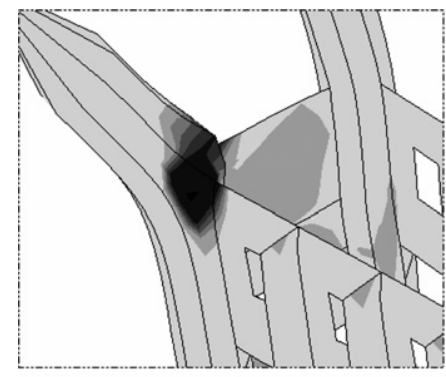

(a)

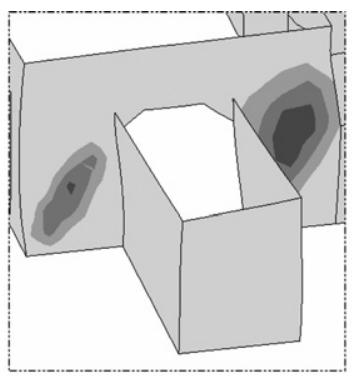

(b)

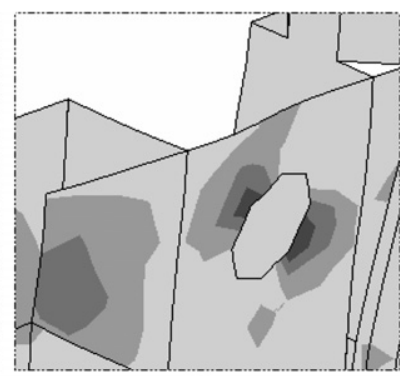

(c)

Fig. 11. Cracking for seismic action along $Z$ axis: (a) tower; (b) wall in the transept; (c) opening in the church main façade. The maximum crack width is around $0.01 \mathrm{~m}$.

Nevertheless, non-linear analyses using the simplified model seem to demonstrate that Monastery of Jerónimos is a safe construction in what concerns the wall behavior under seismic loading. As the vaults have not been properly considered in the model, a conclusion regarding the safety of the vaults is not possible at this stage. 


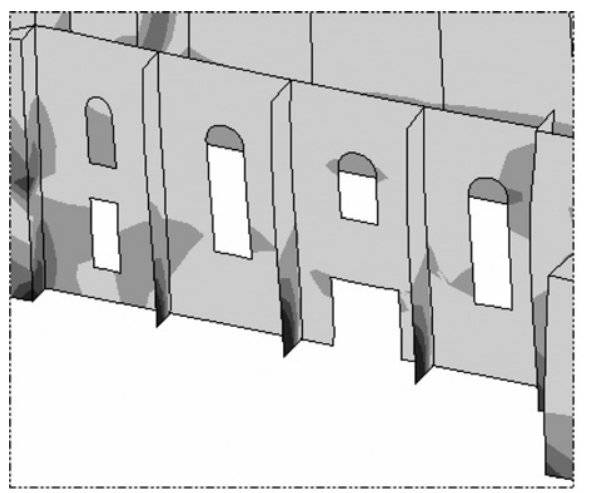

(a)

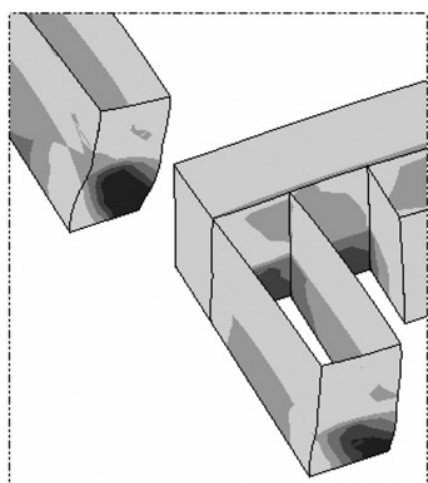

(b)

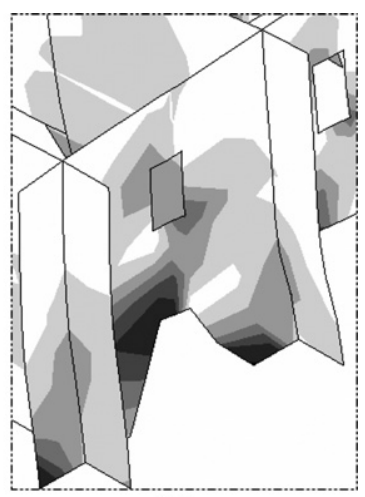

(c)

Fig. 12. Maximum compressive stresses for seismic action along $Z$ axis: (a) buttresses; (b) adjacent bodies to the monument; (c) arcade. The maximum stress compressive is around $4.0 \mathrm{~N} / \mathrm{mm}^{2}$.

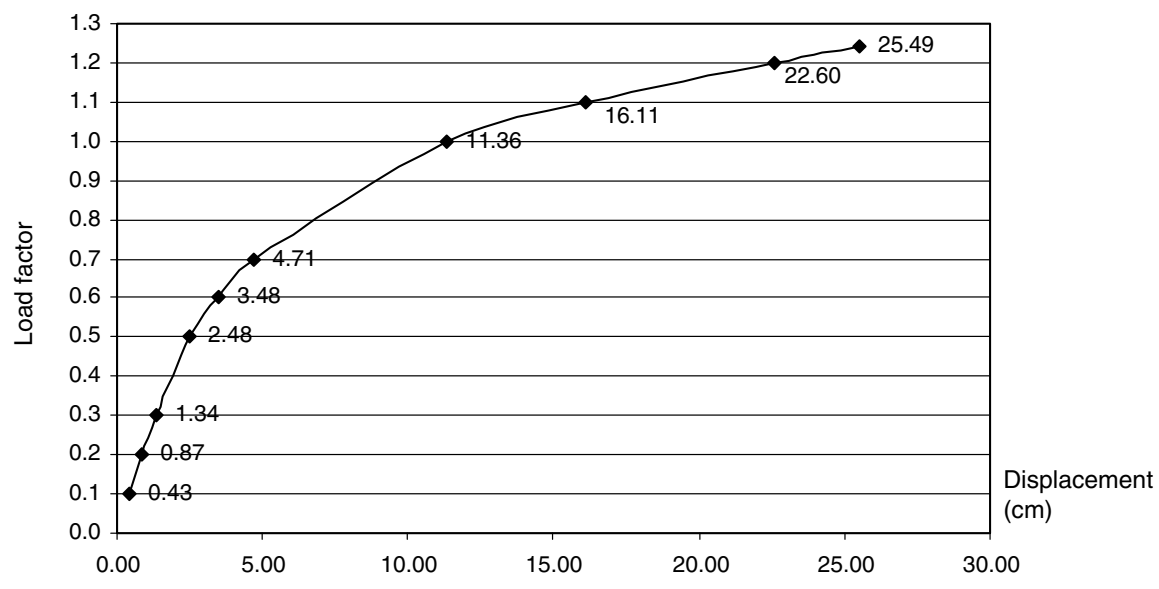

Fig. 13. Force-displacement diagram for seismic action acting along the $Z$ axis.

\section{Detailed structural analysis of the church}

The columns of the church are very slender and exhibit moderate out-of-plumbness. As the model previously adopted for the church was very simplified and the vaults were not adequately represented, more refined models have been adopted for a new study of the church under vertical loading.

The church has considerable dimensions, namely a length of $70 \mathrm{~m}$, a width of $40 \mathrm{~m}$ and a height of $24 \mathrm{~m}$. The plan includes a single bell tower (south side), a single nave, a transept, the chancel and two lateral chapels, see Fig. 14. In order to assess the safety of the church, the following preliminary tasks have been carried out: (a) three-dimensional survey of the church; (b) radar investigation to detect the thickness of the masonry infill in the vault and pier [11]; (c) removal of the roof, visual inspection, bore drilling, metal detection and chemical analysis of materials [11].

The south wall has a thickness of around $1.9 \mathrm{~m}$ and possesses very large openings. Three large trapezoidal buttresses ensure the stability of the wall. The north wall is extremely robust (with an average thickness of around $3.5 \mathrm{~m}$ ). This wall includes an internal staircase that provides access to the cloister. The chancel walls are also rather thick (around 2.5-2.65 m). The nave is divided by two rows of columns, with a free height of around $16.0 \mathrm{~m}$. Each column possesses large bases and fan capitals. The transverse sections of the octagonal columns have a radius of $1.04 \mathrm{~m}$ (nave) and $1.88 \mathrm{~m}$ (nave-transept). The columns seem to be made of a single block or two blocks, for the nave, and four blocks, for the transept. The vaults are ribbed and are connected to 
(a)

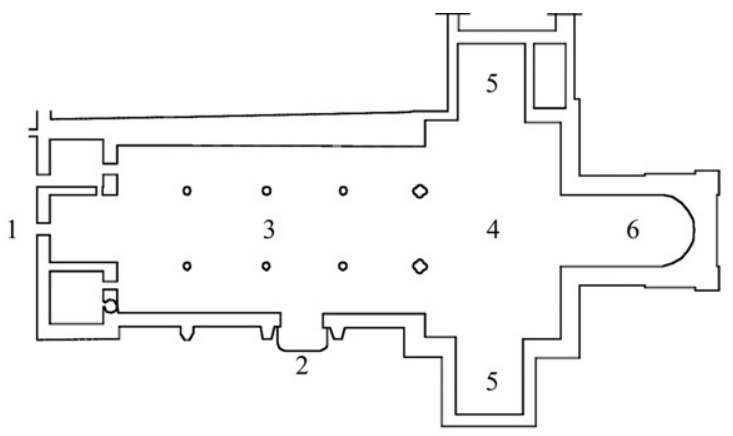

(b)

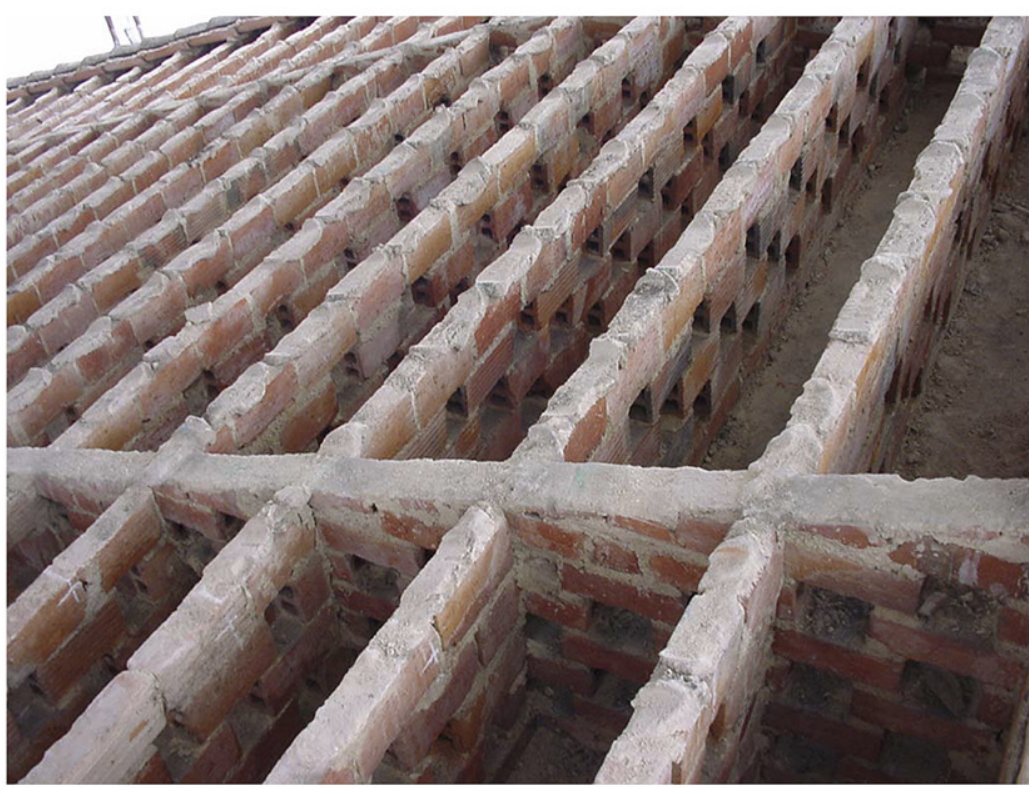

(c)

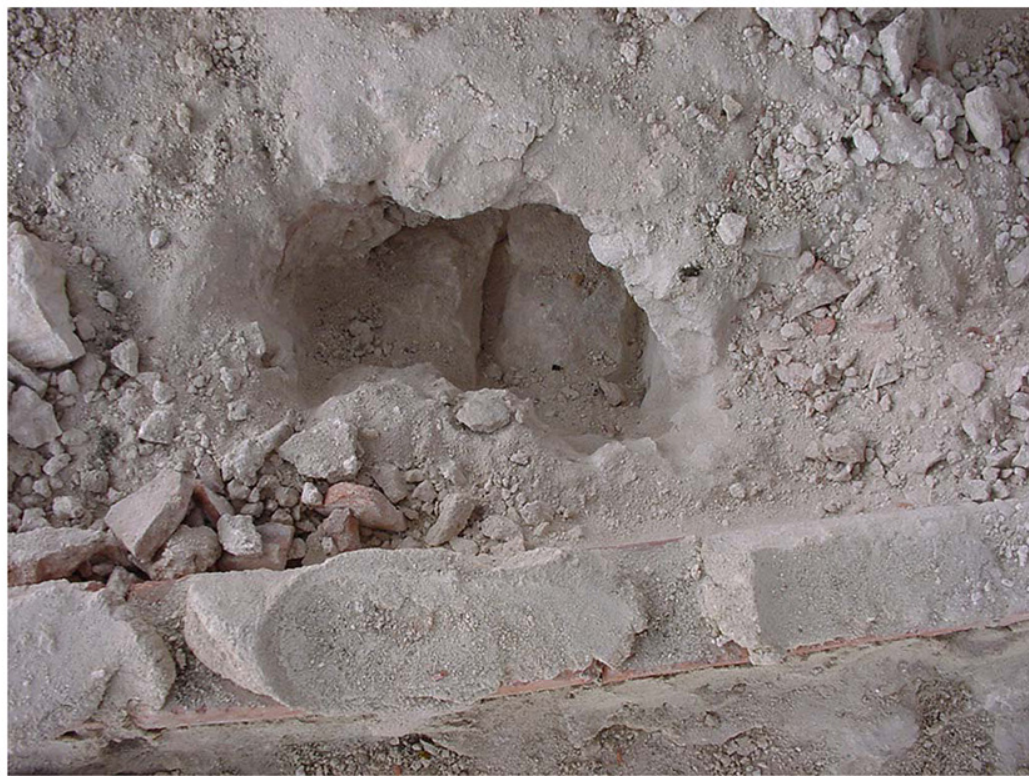

Fig. 14. Survey: (a) plan, with 1 - axial doorway, 2 - lateral doorway, 3 - nave, 4 - transept, 5 - side chapels, 6 - chancel; (b) removal of the roof and existing system to support the roofing tiles; (c) visual inspection of the infill and rib. 


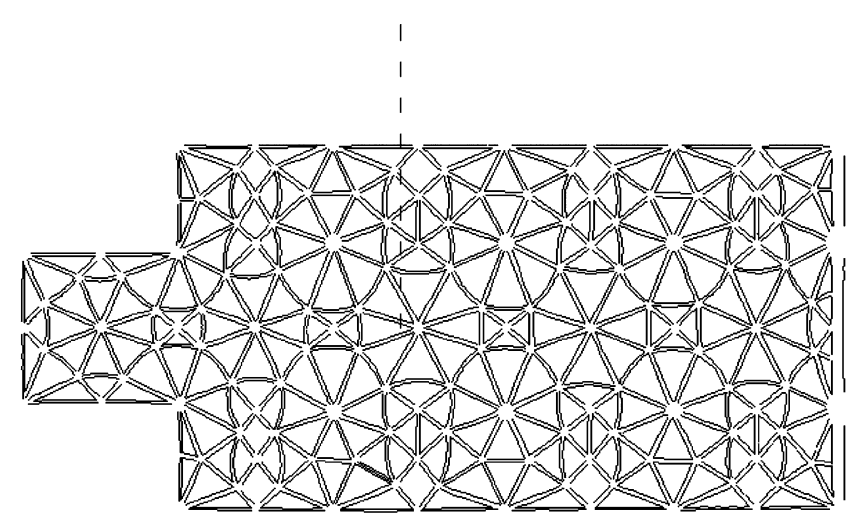

(a)
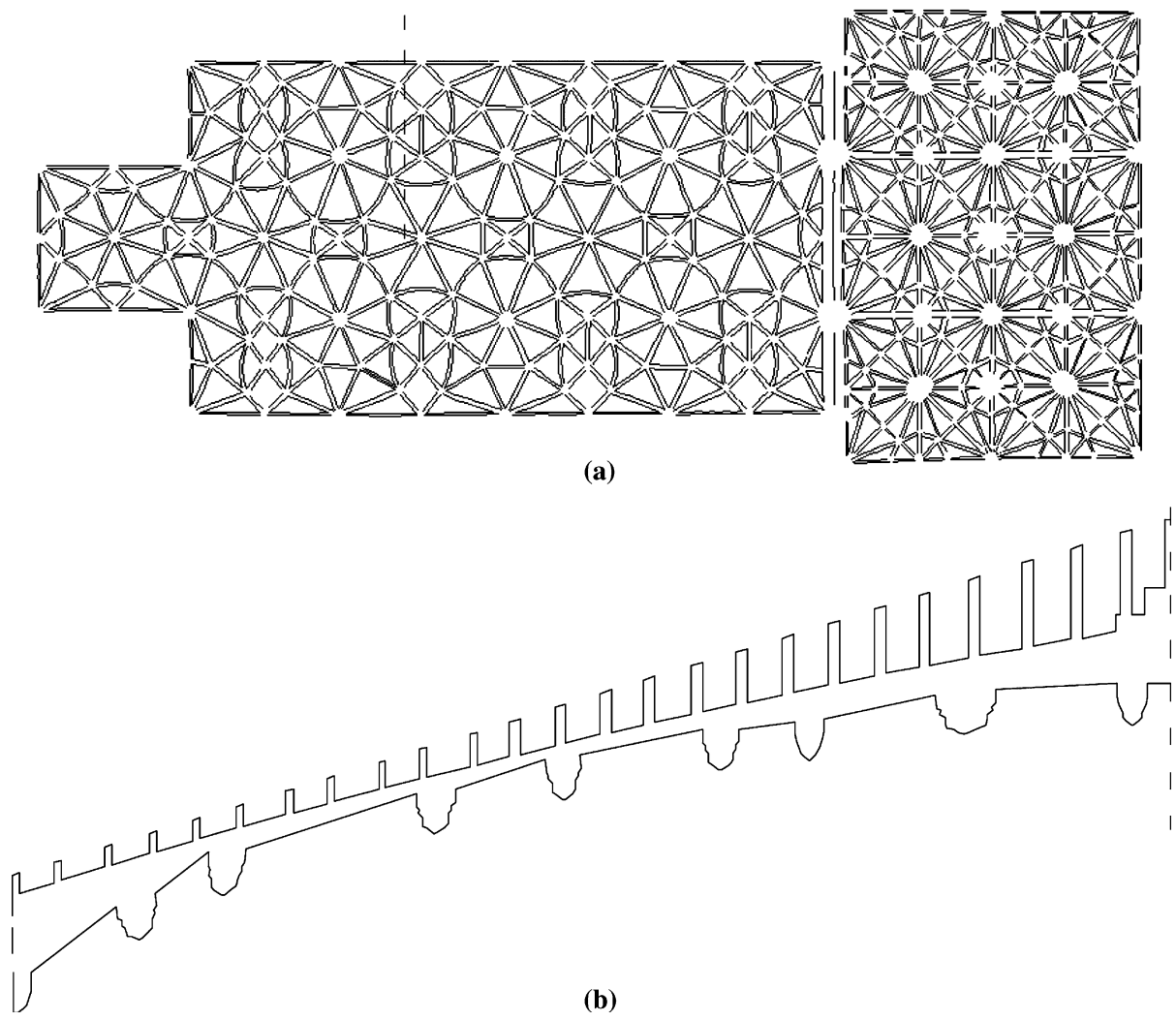

Fig. 15. Aspects of the vaults: (a) plan and (b) transversal cross-section of the nave (only half of the cross-section is shown, due to symmetry conditions at the vault key).

the columns by large fan capitals, see Fig. 15. Cross-section of the nave vault is, mostly, a slightly curved barrel vault, even if supported at the columns. Thin stone slabs are placed on top of the stone ribs. On top of the slabs, a variable thickness mortar layer exists. The part of the slab inside the capital is filled with a concretelike material with stones and clay mortar. On top of the vaults, brick masonry wallets were built during the 1930s to provide support for the roofing tiles.

\subsection{Main nave}

In historical constructions, the borderline between architectural details and structural elements is not always clear. The complexity of the structure addressed in the previous section increases the difficulty in defining a finite element model appropriate for structural analysis. The lack of historical information, and the scarcity of mechanical data, limits the quality of analysis and the interpretation of data. Therefore, the adopted model should not be excessively complex.

The adopted model for the main nave includes the structural detail representative of the vault under the most unfavorable possibility, see Fig. 16a, using symmetric boundary conditions. Therefore, the model represents adequately the collapse of the central-south part of the nave. The model includes three-dimensional volume elements, for the ribs and columns, and curved shell elements, for the infill and stones slabs, see Fig. 16b and c. The external (south) wall was represented by beam elements, properly tied to the volume elements. The supports are fully restrained, being rotations possible given the non-linear material behavior assumed. All elements have quadratic interpolation, resulting in a mesh with 33,335 degrees of freedom. The time-effort necessary for total mesh generation, including definition of supports, loads and thicknesses, can be estimated in three man-months. 


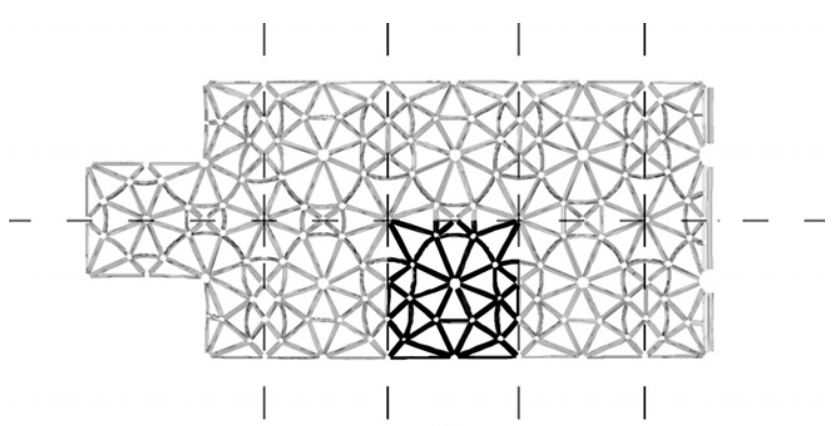

(a)

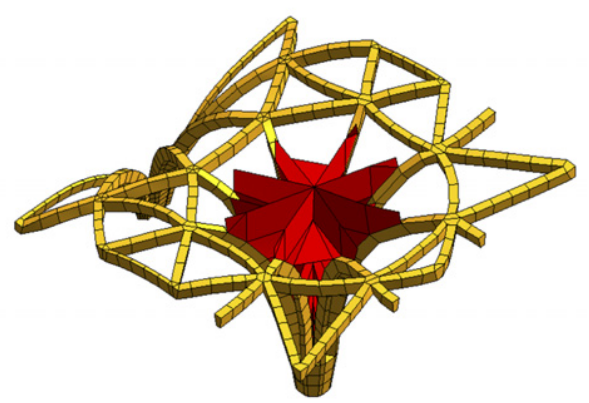

(b)

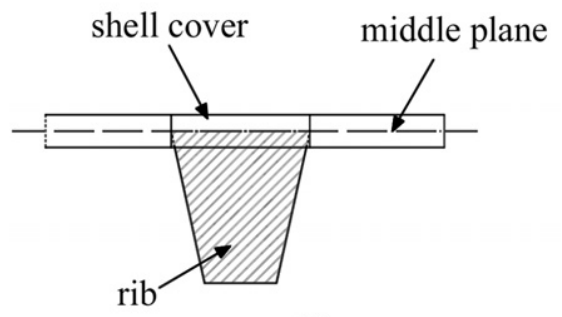

(c)

Fig. 16. Aspects of the model: (a) basic pattern, (b) details around capital and (c) detail of the connection between the rib and infill.

The actions considered in the analysis include only the self-weight of the structure. Two different types of materials have been considered, one type for the stone masonry (Young modulus $E=3000 \mathrm{~N} / \mathrm{mm}^{2}$ and compressive strength $f_{\mathrm{c}}=3.0 / 6.0 /$ infinite $\left.\mathrm{N} / \mathrm{mm}^{2}\right)$ and another type for the rubble infill $\left(E=1000 \mathrm{~N} / \mathrm{mm}^{2}\right.$ and $f_{\mathrm{c}}=0.5 / 1.0 / 2.0 \mathrm{~N} / \mathrm{mm}^{2}$ ). Given the uncertainty about the mechanical properties, a sensitive analysis was carried out, assuming the bold values as the reference values. The tensile strength has been assumed equal to zero for both materials. The material model adopted in the analysis was a total strain crack model with an ideal plastic compression limiter, please consult [12] for details.

The results for the reference analysis $\left(f_{\mathrm{c} \text {,stone }}=6.0 \mathrm{~N} / \mathrm{mm}^{2}\right.$ and $\left.f_{\mathrm{c}, \text { rubble }}=1.0 \mathrm{~N} / \mathrm{mm}^{2}\right)$ are shown in Fig. 17 , in terms of load-displacement diagrams, deformed mesh, maximum principal strain (equivalent to tensile damage) and minimum principal stresses (compression). Further discussion on the results can be found in [13]. Fig. 17a illustrates the load-displacement diagrams for the vault key and top of the column. Here, the load factor represents the ratio between the self-weight of the structure and the applied load. It is possible to observe that the response of the structure is severely nonlinear from the beginning of loading, for the nave, and from a load factor of 1.5 , for the column. The behavior of the nave is justified by the rather high tensile stresses found in the ribs, using a linear elastic model. The collapse of the columns is due to the normal and flexural action. The ultimate load factor is 2.0 , which is low for this type of structures.

The deformed mesh at failure, see Fig. 17b, indicates that the structural behavior is similar to a two-dimensional frame, with a collapse mechanism of five hinges (four hinges at the top and base of the columns and one at the key of the vault. Nevertheless, there is some vault effect with slightly larger displacements at the central 


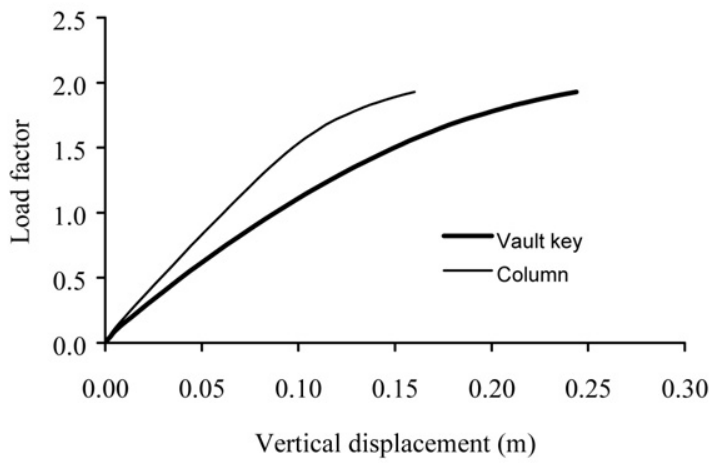

(a)

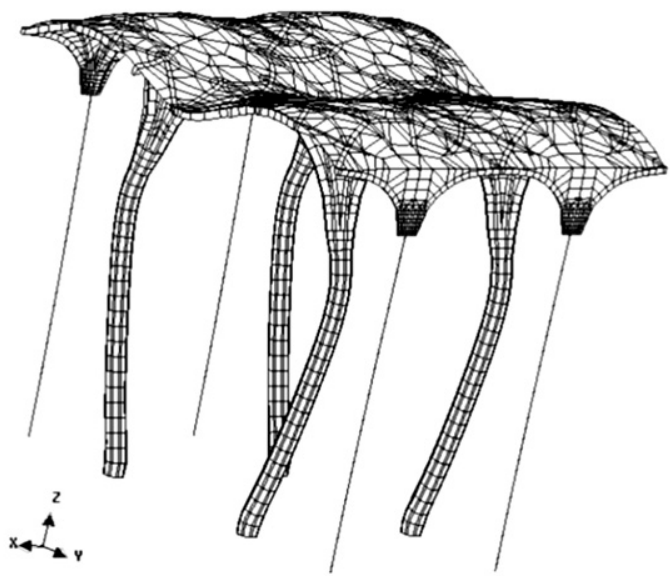

(b)

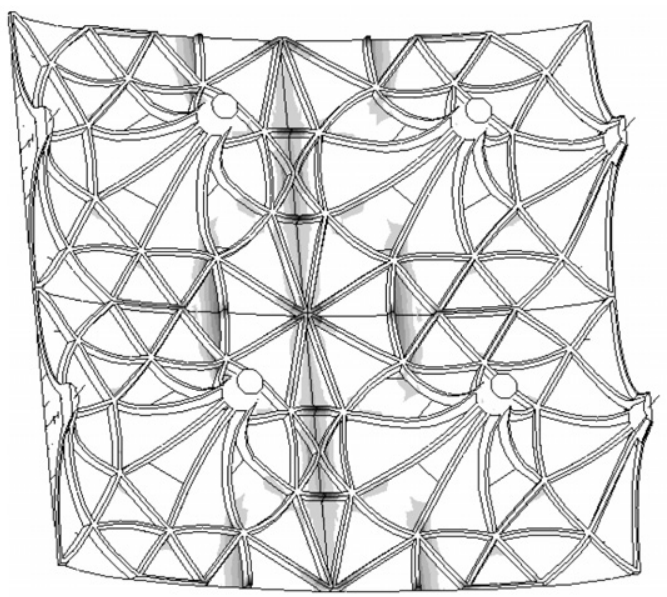

(c)

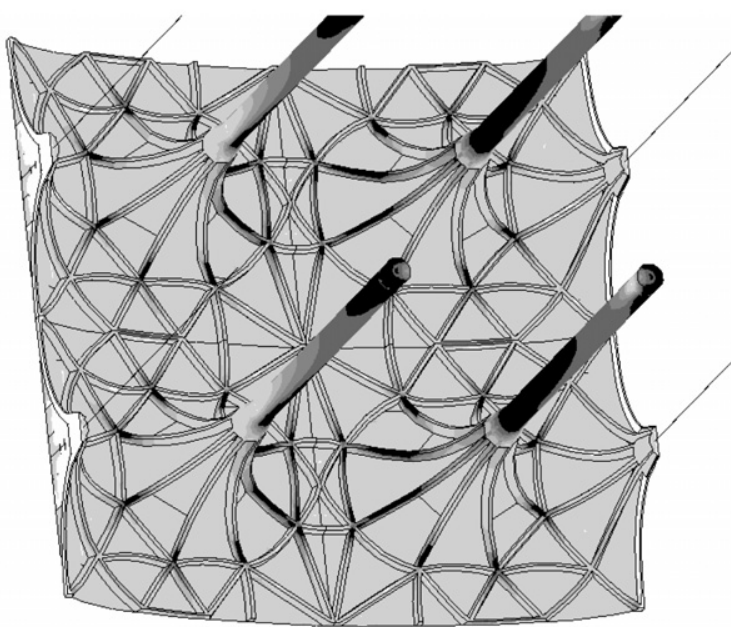

(d)

Fig. 17. Results of nave analysis: (a) load-displacement diagram, (b) incremental deformed mesh at failure, (c) maximum principal strains (equivalent to cracks) and (d) minimum principal stress (compression).

octagon, formed between the four capitals. The stresses are bounded in tension and compression, meaning that cracking and crushing occurs. Fig. 17c illustrates the maximum principal strains, which are related to cracking of the structure. The pairs of transverse ribs that connect the columns (in the central part of the structure) exhibit significant cracking, as well as the infill in the same area. Additional cracking, less exuberant and more diffused, appears in the central octagon defined by the capitals of the four columns. Such cracking occurs at the key of the octagon and in the longitudinal ribs, which confirms the larger displacements of the vault and the bi-directional behavior of the vault. Finally, Fig. 17d illustrates the minimum principal stresses at failure. It can be observed that very high compressive stresses are found in the capital ribs, particularly in the transversal area that connects a pair of columns. The columns exhibit also very high compressive stresses, which lead to the collapse mechanism described before.

Fig. 18 presents the load-displacement diagrams for different compressive strengths of the stone masonry and infill. The influence of the compressive strength of the stone masonry is very significant, as shown in Fig. 18a. The ultimate load factor of the structure is reduced to 1.0 , for a compressive strength of $3.0 \mathrm{~N} /$ $\mathrm{mm}^{2}$, and increased to a value larger than 5.0, for an infinite compressive strength. One the contrary, the influence of the compressive strength of the infill is marginal, as shown in Fig. 18b. The ultimate load factor of the structure is kept constant and only minor changes of stiffness can be observed. The collapse mechanism remains unchanged in all the analyses. 


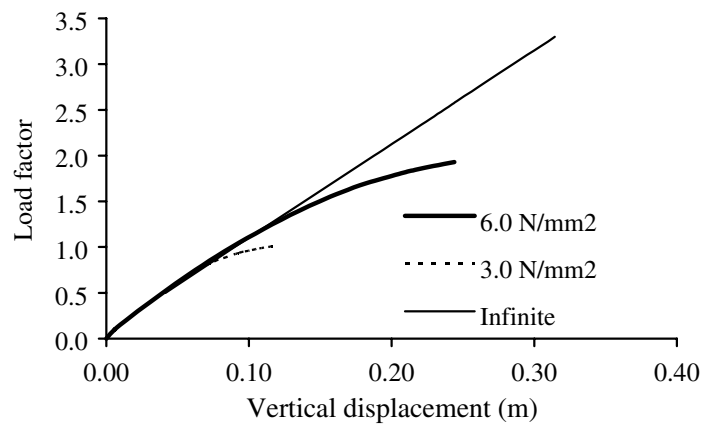

(a)

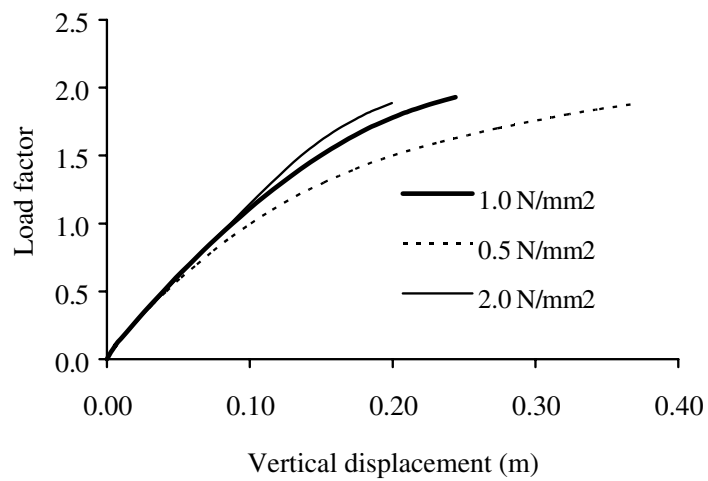

(b)

Fig. 18. Sensitivity analysis: (a) influence of the compressive strength of stone masonry and (b) influence of the compressive strength of the infill.

Finally, Fig. 19 illustrates the influence of the geometrical non-linear behavior in the analysis. It can be observed that this additional non-linear behavior, in the reference analysis, reduces the ultimate load factor to a value of 1.4 , which is rather low. Again, the collapse mechanism remains unchanged.

\subsection{Transept}

The second part of the structural assessment of the church focus on the transept vault. This vault has a geometry and structural scheme different from the nave. In plan, the vault forms a rectangle with $18.8 \times 28.0 \mathrm{~m}^{2}$, using a basic square with a side of $4.7 \mathrm{~m}$ repeated 24 times. The vault exhibits, in plan, straight and circular ribs, together with keys at the intersection, see Fig. 20. The transverse section of the ribs is equal

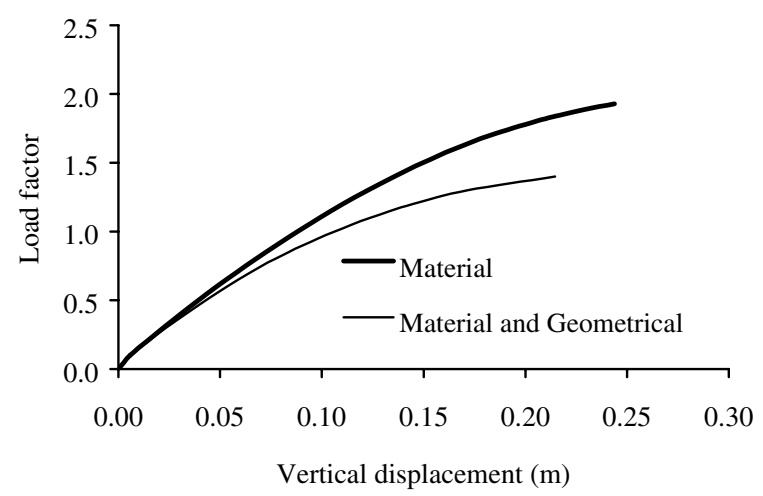

Fig. 19. Influence of geometrical non-linear behavior. 


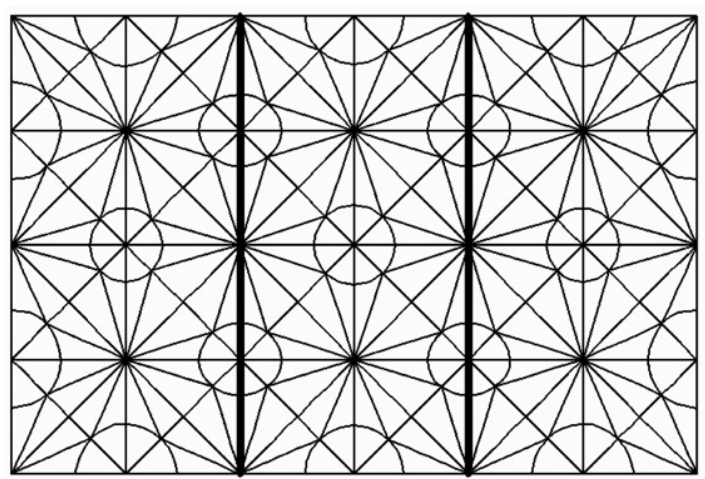

(a)

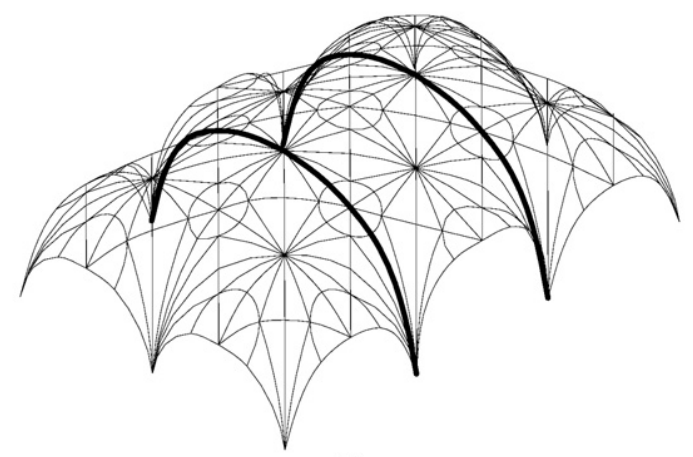

(b)

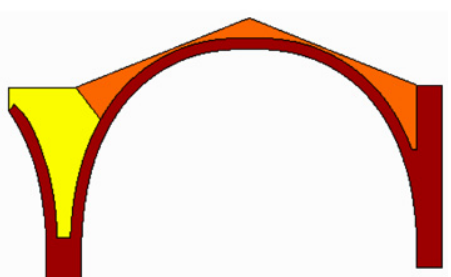

Stone

Vault infill

Capital infill

(c)

Fig. 20. Transept vault: (a) plan, (b) perspective and (c) finite element model.

to $0.4 \mathrm{~m}$ (height) by $0.28 \mathrm{~m}$ (width), with the exception of the two central ribs (arches) indicated with a thick line in Fig. 20a, showing a cross section of $0.60 \times 0.40 \mathrm{~m}^{2}$. Therefore, the two arches are the most significant structural elements of the transept vault. Given the complexity of the vault and the time consumed in the model of the nave, a simplified two-dimensional model of these arches was adopted for the structural analysis. The time-effort necessary for total mesh generation, including definition of supports, loads and thicknesses, can be estimated in one man-week. Fig. 20c illustrates the conservative adopted model, which includes the arch, the infill, the nave column and the external wall, with appropriate stiffness values and boundary conditions, see [13] for a complete description. All elements have quadratic interpolation, resulting in a mesh with 3530 degrees of freedom. Again, the actions considered in the analysis include only the self-weight of the structure. For the materials, the reference values described previously are adopted.

The results for the transept analysis are shown in Fig. 21, in terms of maximum principal strain (equivalent to tensile damage) and minimum principal stresses (compression), depicted on the deformed mesh. The ultimate load factor is 1.7, which is again rather low for this type of structures, even if the model is simplified and conservative. Collapse occurs with a typical four hinges mechanism, being three hinges located in the vault and one hinge located in the right support, see Fig. 21. The collapse involving the right wall occurs due to the consideration that the nave prevents inwards movement of the (left) column. Fig. 21a indicates that the arch is cracked at the key (intrados) and both quarter spans (extrados). Significant cracking is also present in the right support. Fig. $21 \mathrm{~b}$ demonstrates that compressive stresses concentrate in the arch and in the base of the right wall. The compressive stresses in the left column are moderate and do not govern collapse.

\subsection{Columns}

A simple hand calculation can provide further insight about the stability of columns, which seem to be a key issue for the nave. The axial load in the columns of the nave $N_{\text {applied }}$ is around $2455 \mathrm{kN}$. For a Young's modulus $E$ equal to $3000 \mathrm{~N} / \mathrm{mm}^{2}$, a compressive strength $f_{\mathrm{c}}$ equal to $6 \mathrm{~N} / \mathrm{mm}^{2}$, a diameter $\phi$ equal to $1.04 \mathrm{~m}$, a 

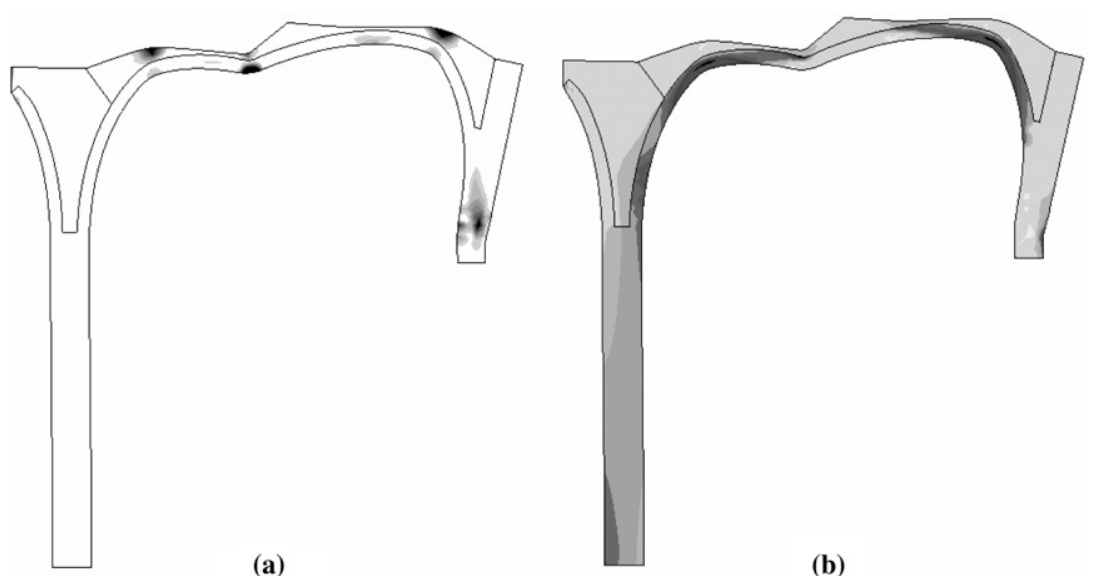

Fig. 21. Results of transept analysis at collapse: (a) maximum principal strains (equivalent to cracks) and (b) minimum principal stress (compression), depicted on deformed meshes.

length of the column $l$ equal to $15.75 \mathrm{~m}$ and an assumed buckling length $l_{0}$ equal to $1.5 l$, it is possible to calculate the ultimate load hi the column $N_{\max }$ and a material safety factor $\mathrm{SF}_{\mathrm{m}}$, given by

$$
N_{\max }=f_{\mathrm{c}} \times \frac{\pi \times \phi^{2}}{4}=5097 \mathrm{kN} \Rightarrow \mathrm{SF}_{\mathrm{m}}=\frac{N_{\max }}{N_{\text {applied }}}=\frac{5097}{2455}=2.08 .
$$

The buckling load in the column $N_{\text {Euler }}$ and a geometrical safety factor $\mathrm{SF}_{\mathrm{g}}$ are given by

$$
N_{\text {Euler }}=\frac{\pi^{2} \times E \times \frac{\pi \times \phi^{4}}{64}}{l_{0}^{2}}=3046 \mathrm{kN} \quad \Rightarrow \mathrm{SF}_{\mathrm{g}}=\frac{N_{\max }}{N_{\text {applied }}}=\frac{3046}{2455}=1.24
$$

These values are rather close to the values found in the numerical analysis and confirm that the columns of the nave are too slender. Therefore, more insight is required regarding the mechanical properties of the masonry constituting the columns. It is stressed that the value adopted for the buckling length is a mere assumption and that the ultimate load factor of 1.4 found in the numerical analysis incorporates both the material and geometrical effects.

For the columns between the nave and the transept, with a diameter $\phi$ equal to $1.88 \mathrm{~m}$ and a length $l$ equals to $16.38 \mathrm{~m}$, similar calculations yield a material safety factor $\mathrm{SF}_{\mathrm{m}}$ equal to 3.45 and a geometrical safety factor $\mathrm{SF}_{\mathrm{g}}$ equal to 6.23 . These values confirm that the collapse is not related with the columns.

\subsection{Conclusions}

The Church of Jerónimos has been in use for some hundred years with moderate damaged ribs, and moderate tilting of the columns and sidewalls. The information available about the mechanical properties of the material and internal constitution of the structural elements is scarce, and a sensitivity analysis of the results was carried out. Nevertheless, the different numerical analysis carried out allowed to conclude that: (a) collapse of the nave occurs with a failure mechanism involving the columns and the vault; (b) collapse of the transept occurs with a failure mechanism involving the external walls and the vault; (c) the compressive strength of masonry is a key factor for the response of the nave; (d) the safety of the structure seems low, when compared with similar constructions; (e) the columns of the nave are too slender.

\section{Additional in situ investigations in the church}

Possible remedial measures in the church, as a result from the numerical simulations provided above, require a careful judgment. Given the cultural importance of the construction, the safety of the users, the seismic risk and the accumulation of physical, chemical and mechanical damage, complementary NDT and 


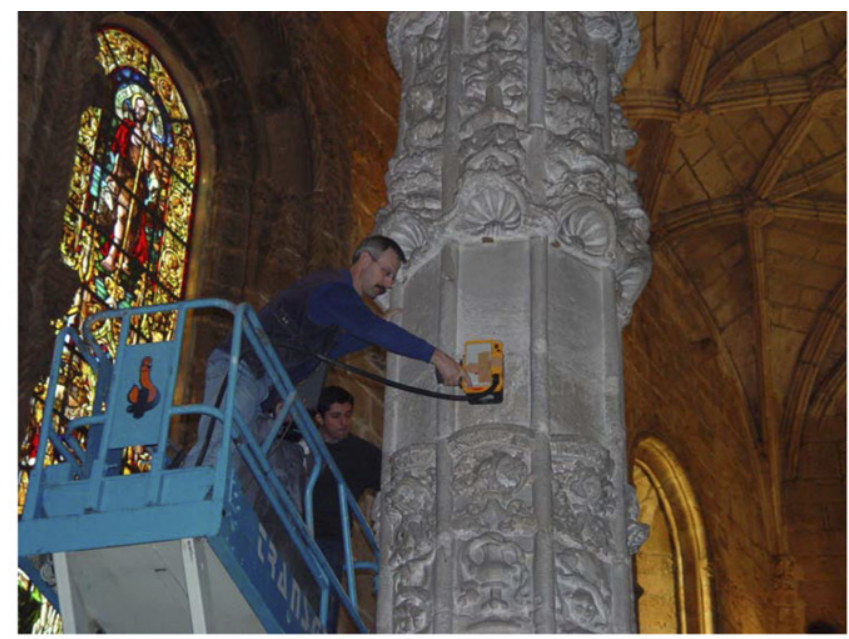

(a)
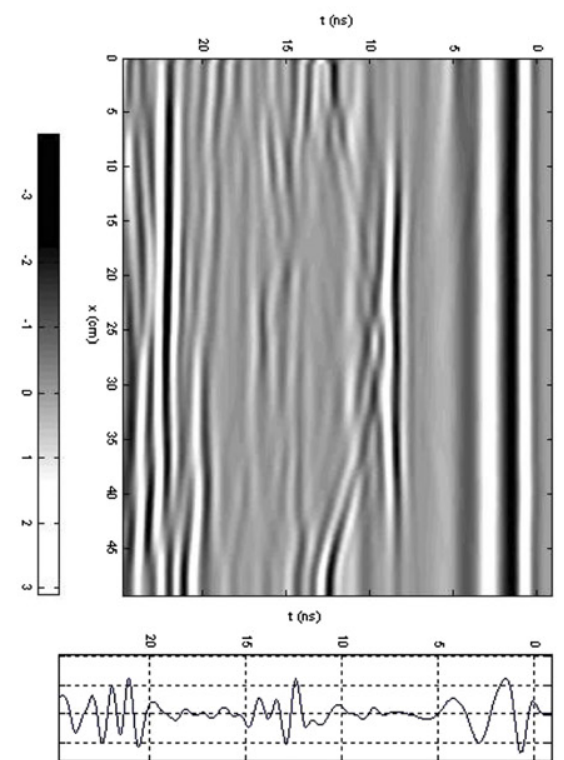

(b)

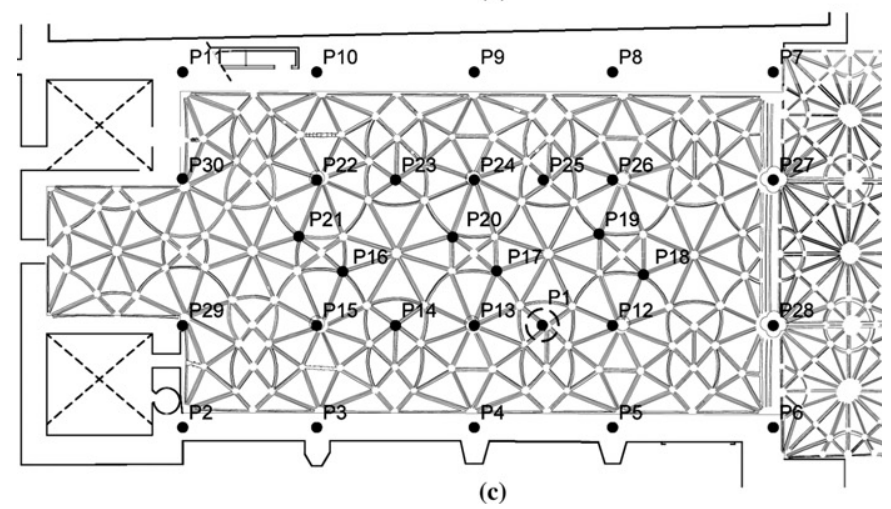

Fig. 22. Examples of in situ additional measurements for validation of numerical analysis: (a,b) GPR investigation of the columns, (c, d) dynamic modal investigation and $(\mathrm{e}, \mathrm{f})$ monitoring system with remote access. 


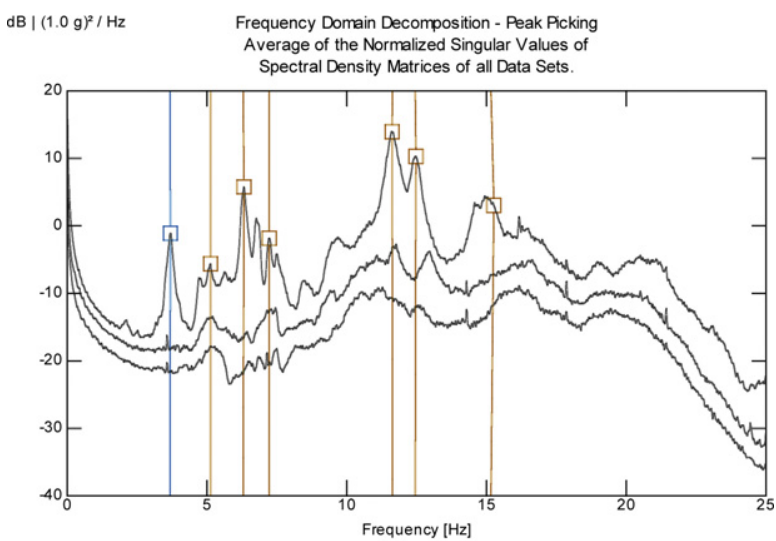

(d)
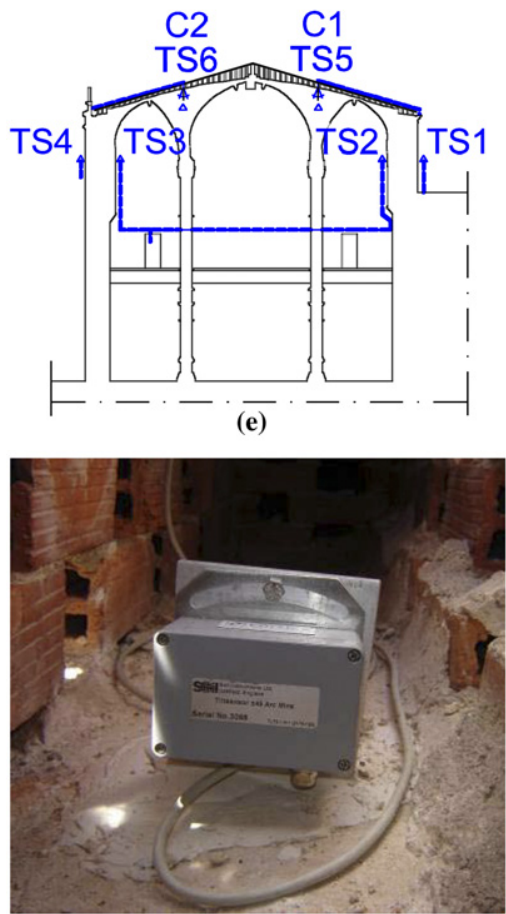

(f)

Fig. 22 (continued)

monitoring were proposed, see Fig. 22. Validation and possible correction of the numerical results obtained previously seem essential to define possible future remedial measures on the columns of the church.

Given the major influence of the columns in the structural response of the columns, a radar inspection was carried out aiming at defining their internal constitution, see Fig. 22a and b. Radar measurements were performed in the four columns of the Church that feature larger slenderness, see [14] for details. This allowed to confirm that the columns are homogeneous, constituted by segments of a single block or two/three blocks with thin vertical joints. Therefore, it seems reasonable to assume a moderately high strength for the masonry of the columns. Tests are planned in such masonry to obtain a more reliable value. In addition, two monitoring systems have been installed in the main nave of the church, see [15], with the following objectives: (a) to better understand the structural behavior of the complex construction; (b) to identify any possible progressive phenomenon; (c) to detect damage at an earlier stage; and (d) to calibrate the boundary conditions and the modulus of elasticity of numerical models. 


\subsection{Dynamic identification}

Output-only modal identifications techniques were used to estimate the modal parameters: resonant frequencies, mode shapes and damping coefficients. These techniques are based on the dynamic response measurements of a virtual system under the natural (ambient or operational) conditions, and they are based on the assumption that the excitations are reasonable random in time and in the physical space of the structure. Two techniques were applied to compare the estimated dynamic parameters in order to have more accurate results: the enhanced frequency domain decomposition (EFDD) and the stochastic subspace identification (SSI) method, see $[16,17]$.

According to the results of a preliminary numeric modal analysis with a simplified three-dimensional beam element model for the church, 30 points on the top of the main nave were selected to measure the acceleration response. Ten points are localized on the top of the external walls with the purpose to measure the nave boundaries constrains and also the global dynamic response of the church. The other points are located either on the top of the columns or on the top of the vaults keys. To ensure adequate selection of the reference point for all measurements, preliminary signal measurements were done and it could be concluded that point P1 was the one with more significant signal vibration amplitudes, see Fig. 22c. For every measured point, the roof tiles were removed and the signal acquisition was done directly on the top of the nave (extrados) to avoid any possible noise signals from the roof structure. The eight estimated mode shapes and frequencies are given in [15], see Fig. 22d. Currently the numerical model is being updated to reproduce the frequencies and modes measures in situ.

\subsection{Monitoring}

The static monitoring system aims at measuring deformations and temperature variations of two columns in the main nave. The measurement system is focused on the columns structural observation because these elements determine the nave structural behavior. The static monitoring system is composed by:

- Six temperature sensors (TS1 to TS6), model SKTS 200/U form SKYE INSTRUMENTS, with a measurement range from -20 to $100{ }^{\circ} \mathrm{C}$ and measurement resolution of $0.2^{\circ} \mathrm{C}$. Four sensors were installed in the side north and south walls and two sensors were installed on the top of the columns and in the nave extrados;

- Two uniaxial tilt meters $(\mathrm{Cl}$ and $\mathrm{C} 2)$, model TLT2 from SOIL INSTRUMENTS, with a measurement range of $\pm 1.5^{\circ}$ and a resolution of $0.03^{\circ}$. The two tilt meters were installed on the top of the columns with larger vertical out-of-plumbness and in the extrados of the nave. The measurement orientation is the transverse direction of the nave;

- One data logger (D) for the data acquisition and data record, model CR1 OX from CAMPBELL, with a GSM modem from WAVECOM, which allows the data remote downloading by phone line. The data logger is located inside an ambient protection box in the bell tower.

The sampling rate will be one reading per hour in order to observe the temperature variation during the daily cycle. The temperature sensors are distributed in the structure to evaluate the effect of the temperature gradient in the response of the structure. The static monitoring system was fully installed in the end of May 2005 and will allow to measure any additional rotation of the columns.

Due to the different technical characteristics and sampling rates data acquisitions, the dynamic monitoring system is physically separated from the static one. The system is composed by two strong motions recorders; model GSR-18 from GEOSIG; an 18 bits AD converter analyzer. One triaxial force balance accelerometer is connected to each analyzer. The accelerometers, model AC-63 from GEOSIG, have a bandwidth form DC to $100 \mathrm{~Hz}$, a dynamic range $\pm 1 \mathrm{~g}$ and a sensitivity of $10 \mathrm{~V} / \mathrm{g}$. The two devices connected give final a resolution of $8 \mu \mathrm{g}$. The sensors were installed on the base of the structure near the chancel and at the top of the main nave (extrados), between two consecutive columns and in the locations with higher signal levels in the dynamic modal identification analysis. The two recorders are connected by an enhanced interconnection network, which allows a common trigger and time programmed records. Each recorder works independently and the 
data are stored locally in every recorder. The dynamic system is in operation since April 2005 and will allow to measure significant dynamic events and to permanently measure changes in the frequency peaks.

\section{Conclusions}

The results obtained from advanced numerical simulations in historical structures are usually important for understanding their structural behavior. As a rule, advanced modeling is a necessary means for understanding the behavior and damage of (complex) historical constructions but this requires specialized consulting engineers and extensive information about the material. Numerical models can also be used as a numerical laboratory, where the sensitivity of the results to input material parameters, boundary conditions and actions is studied, and may be invaluable in the conception and understanding of in situ testing and monitoring. This has been demonstrated using a case study in the crown asset of the Portuguese architectural heritage: Monastery of Jerónimos, in Lisbon. It is stressed that remedial measures in cultural heritage buildings require an iterative approach, aiming at gathering the information necessary to issue a proper judgment. Excessive in situ measurements have high costs that might compromise a study, but scarce in situ measurements might have unbearable costs due to inadequate, heavy and invasive remedial measures.

\section{Acknowledgements}

The authors gratefully acknowledge the support of the European-Indian Economic Cross Cultural Programme, under Contract ALA/95/23/2003/077-122, "Improving the Seismic Resistance of Cultural Heritage Buildings". The third author was also partially supported by the Portuguese Science and Technology Foundation (FCT) by the Grant No. SFRH/BD/6409/2001.

\section{References}

[1] Lourenço PB. Experimental and numerical issues in the modeling of the mechanical behavior of masonry. Structural analysis of historical constructions. Barcelona: CIMNE; 1998. p. 57-91.

[2] Rots JG, editor. Structural masonry: an experimental/numerical basis for practical design rules. Rotterdam: AA Balkema; 1997.

[3] Lourenço PB. Computations of historical masonry constructions. Prog Struct Eng Mater 2002;4(3):301-9.

[4] ICOMOS. Recommendations for the analysis, conservation and structural restoration of architectural heritage; 2001.

[5] DGEMN. Inventory of architectural heritage; 2005. Available from: www.monumentos.pt.

[6] Genin S. The nave vault of the Hieronymites Monastery Church in Lisbon. In: Proceedings of the third international seminar on historical constructions, Guimarães: 2001. Guimarães: University of Minho; 2001. p. 293-302. Available from: www.civil.uminho.pt/ masonry.

[7] CEN. EN 1998-3 Eurocode 8: Design of structures for earthquake resistance - Part 3: Strengthening and repair of buildings; 2005.

[8] Dyngeland T, Vaz CT, Pinto A. Linear dynamic analyses of the São Vicente de Fora monastery in Lisbon, Portugal. Report no. I.97.18. Lisbon: LNEC; 1997.

[9] Mourão S. Study on the seismic behavior of the Monastery of Jerónimos. MSc. dissertation, Universidade do Minho, Guimarães; 2001 [in Portuguese]. Available from: www.civil.uminho.pt/masonry.

[10] Meli R. Structural engineering of historical buildings. Mexico-City: Fundación ICA; 1998 [in Spanish].

[11] Mun M. Study of the constitution of the vaults in the Church from the Monastery of Jerónimos using radar and complementary diagnosis methods. Report no. 176/2002. Lisbon: LNEC; 2002 [in Portuguese].

[12] TNO Building and Construction Research. DIANA finite element analysis, User's manual - Release 8.1. Delft: The Netherlands; 2002.

[13] Lourenço PB, Krakowiak KJ. Stability assessment of the vaults from the Church of Monastery of Jerónimos. Report 03-DEC/E-02, University of Minho, Guimarães; 2003 [in Portuguese].

[14] Fernandes FM. Assessment of two novel NDT techniques: microdrilling and ground penetrating radar. PhD dissertation, University of Minho, Guimarães; 2006. Available from: www.civil.uminho.pt/masonry.

[15] Ramos LF, Lourenço PB. Static and dynamic structural monitoring of the Santa Maria of Belém Church, in Lisbon. In: Proceedings from II ECCOMAS thematic conference on smart structures and materials, Lisbon: 2005. Lisbon: Technical University of Lisbon; 2005. CD-ROM.

[16] Brincker R, Ventura C, Andersen P. Damping estimation by frequency domain decomposition. In: Proceedings of the 19th international modal analysis conference, Kissimee; 2001.

[17] Rodrigues J. Stochastic modal identification, methods of analysis and applications in civil engineering structures. PhD dissertation, FEUP, Porto; 2004 [in Portuguese]. 